ISSN: 0213-2060

DOI: http://dx.doi.org/10.14201/shhme2016345987

\title{
«PODEROSO EN PARIENTES E RENTAS»: CONCEPTOS, DISCURSOS Y PRÁCTICAS SOBRE EL LINAJE EN LOPE GARCÍA DE SALAZAR ${ }^{1}$
}

\author{
Poderoso en parientes e rentas: Concepts, Discourses and Practices \\ about Lineage on Lope García de Salazar
}

\author{
Arsenio DACOSTA \\ Depto. de Psicología Social y Antropología. Facultad de Ciencias Sociales. Universidad de Salamanca. Edificio \\ F.E.S., Avda. Francisco Tomás y Valiente, s/n. E-37007 SALAMANCA. C. e.: adacosta@usal.es
}

Recibido: 2016-04-10

Revisado: 2016-10-10

Aceptado: 2016-10-14

RESUMEN: Para abordar la cuestión del poder de la nobleza en la baja Edad Media se ha tomado como foco el linaje a partir de las obras del pariente mayor e historiador Lope García de Salazar. El linaje es clave para entender la naturaleza de dicho poder, así como los valores, prácticas y capacidad de reproducción social de la nobleza. Para ello se utiliza analíticamente el concepto de habitus, tomado de Pierre Bourdieu, valorando hasta qué punto puede servir al historiador.

Palabras clave: Linaje; Habitus; Nobleza; Poder.

ABSTRACT: The matter of the power of nobility in the Late Middle Ages is dealt with focusing on lineage/lignage in the works of the elder and historian Lope García de Salazar.

1 Este trabajo forma parte de los resultados del proyecto de investigación De la Lucha de Bandos a la hidalguía universal: transformaciones sociales, politicas e ideológicas en el País Vasco (siglos XIV y XV) financiado por el Ministerio de Economía y Competitividad (HAR2013-44093-P), e integrado en las actividades del Grupo de Investigación del Gobierno Vasco Sociedad, poder y cultura (IT-600-13). Nuestro más sincero agradecimiento a Manuel González de Ávila y a José Ramón Díaz de Durana por sus valiosas sugerencias. 
ARSENIO DACOSTA

Lineage is key to understanding the nature of that power, as well as nobility's values, practices and ability for social reproduction. To this purpose Pierre Bourdieu's concept of habitus is used analytically, evaluating the extent to which it can be useful to the historian.

Keywords: Lineage/lignage; Habitus; Nobility; Power.

SUMARIO: 1 Del concepto al habitus. 2 La incorporación. 3 La racionalidad. 4 La reproducción. 5 La representación. 6 La objetivación. 7 Referencias bibliográficas.

«El historiador social que intenta comprender las instituciones feudales debe estudiarlas en un lugar de Europa hasta adquirir todo el conocimiento que pueda acerca de ellas [...].

No buscará leyes sino patrones significativos.»

Sir Edward E. Evans-Pritchard ${ }^{2}$

Si hay una institución social que caracteriza a la nobleza peninsular a finales de la Edad Media, esa es el linaje. Institución en el sentido antropológico del término ${ }^{3}$ o, si se prefiere, una estructura estructurada predispuesta a funcionar como estructura estructurante citando a Bourdieu 4 . Nuestro enfoque será, pues, interpretar el linaje como elemento central del habitus de clase $e^{5}$ de la nobleza ${ }^{6}$ castellana bajomedieval y, en consecuencia,

2 Ensayos de Antropología Social. Madrid: Siglo XXI, 1990, p. 20.

3 Para Alfred R. RADCLIFFe-BRown «las instituciones sociales, en el sentido de modos regularizados de conducta, constituyen la maquinaria mediante la cual una estructura social, una red de relaciones sociales, mantiene su existencia y su continuidad» (Estructura y función en la sociedad primitiva. Barcelona: Península, 1974, p. 228). A pesar de los muchos matices y del abierto anti-historicismo de Radcliffe-Brown, esta es una definición comúnmente aceptada en Antropología. Para este autor, una de esas estructuras -o funciones- la conforma el parentesco, conformado a su vez por diversas instituciones, entre ellas, el linaje. A pesar de sus críticas, hasta Claude Lévi-STRAuss admitía esta perspectiva (Las estructuras elementales del parentesco. Barcelona: Paidós, 1998, en especial, pp. 25-26).

4 Bourdieu, Pierre. Le sens pratique. Paris: Minuit, 1980, p. 88; y, del mismo, Esquisse d'une théorie de la pratique. Précédé de trois études d'ethnologie Kabyle. Ginebra: Droz, 1972, pp. 175 y ss.

5 La literatura sobre la teorización bourdiesiana es inmensa, pero la ligazón del concepto de habitus con la filosofía aristotélica y con la escolástica medieval nos anima en este enfoque. Para estos nexos y otros con Leibniz, Weber, Elías, Weber, Mauss o Panofsky, véase Burke, Peter. ¿Qué es la historia cultural? Barcelona: Paidós, 2006, p. 77. Sobre la definición agonal de clase social en Bourdieu, véase: WACQuANT, Loïc. «Symbolic power and group-making: on Pierre Bourdieu's reframing of class». Journal of Classical Sociology, 2013, vol. 13, n.o 2, pp. 274-291.

6 La distinción entre aristocracia y nobleza dista de estar resuelta, por mucho que Joseph Morsel apueste por la primera (La aristocracia medieval: La dominación social en Occidente (siglos V-XV). València: Universitat de València, 2008, pp. 13-14). No abordaremos aquí la cuestión, pero en este trabajo entendemos por nobleza los miembros de los grupos dominantes cuya posición está sancionada socialmente. Esto es absolutamente nítido 
ARSENIO DACOSTA

«PODEROSO EN PARIENTES E RENTAS»: CONCEPTOS, DISCURSOS Y PRÁCTICAS SOBRE EL LINAJE EN LOPE GARCÍA DE SALAZAR

como una de las claves para entender la naturaleza de su poder y su capacidad de reproducción social ${ }^{7}$. Valorar hasta qué punto puede servir este utillaje conceptual al historiador es uno de los objetivos de este artículo.

El presente no es nuestro primer acercamiento a la materia. Recientemente hemos tratado la cuestión en relación a lo que hemos denominado la «ilusión agnática» -parafraseando también a Bourdieu-, asunto que, en nuestra modesta opinión, sigue constrińendo los estudios sobre ese objeto de investigación que llamamos "parentesco»"

en las obras del autor que trabajaremos aquí, toda vez que Lope García de Salazar identifica explícita o implícitamente como «nobles» o «hidalgos» a los protagonistas de sus narraciones y, cuando estos no tienen esa consideración -a juicio del autor-, este lo señala expresamente en relación al origen de determinados linajes, por ejemplo, «su fundamiento fue de omes comunes» (Otańes) o "de escuderos de baxa manera» (Setién) (Libro, pp. 769, 780, respectivamente).

7 En su diversidad, «el verdadero vehículo de comprensión de las familias con poder y de los mecanismos que éstas utilizan para lograr sus objetivos de reproducción, es el linaje» (CHAcón JimÉnez, Francisco. «Propuestas teóricas y organización social desde la Historia de la Familia en la España Moderna». Studia Historica. Historia Moderna, 1998, vol. 18, p. 25).

8 En el ámbito del medievalismo no es común el recurso a este utillaje; apunta hacia ello Pérez, Mariel. «En torno a las estructuras de parentesco de la aristocracia castellanoleonesa. Revisión de los modelos interpretativos dominantes». Anales de Historia Antigua, Medieval y Moderna, 2010, vol. 42, pp. 153-174. Fuera del ámbito peninsular, la noción de habitus es central en algunos trabajos como el de Crouch, David. The Birth of Nobility: Constructing Aristocracy in England and France, 900-1300. New York: Routledge, 2014. También lo utiliza Robert Folger para interpretar uno de los sentidos de la obra principal de Fernán Pérez de Guzmán (Generaciones y semblanzas: Memory and Genealogy in Medieval Iberian Historiography. Tübingen: Gunter Narr, 2003, p. 88). Por el contrario, el concepto ha tenido una buena acogida en el modernismo peninsular. De forma más o menos expresa lo utilizan para lo que nos ocupa, la nobleza: ConTreras Contreras, Jaime. «Linaje y cambio social: la manipulación de la memoria». Historia Social, 1995, vol. 21, pp. 105-124; Hespanha, António Manuel. História de Portugal. Dir. José Mattoso. Vol. 4: o Antigo Régime (1620-1807). Lisboa: Estampa, 1997, en especial, pp. 14 y ss.; Guillén Berrendero, José Antonio. «La tratadística nobiliaria como espejo de nobles. El ejemplo de Juan Benito Guardiola y su Tratado de Nobleza de 1591». Brócar, 2002, vol. 26, pp. 81-106; CASEY, James. «La invención de la comunidad y la historia social». Pedralbes. Revista d'Història Moderna, 2003, vol. 23, n. 2, pp. 779-796; y, más recientemente, HeRnández Franco, Juan y Rodríguez Pérez, Raimundo A. «Estrategias, prácticas y actores: avances en los estudios sobre linajes castellanos, a partir de la sociohistoria». Magallánica. Revista de Historia Moderna, 2015, vol. 2, pp. 7-29. Aunque queda fuera del Antiguo Régimen, quisiéramos señalar también González Cuevas, Pedro Carlos. «Habitus e ideología. El pensamiento político de Francisco Moreno y Herrera, Marqués de la Eliseda». Cuadernos de Historia Contemporánea, 1996, vol. 18, pp. 83-114.

9 Una revisión crítica en: DACOSTA, Arsenio. «De la anomalía a lo extraordinario: nobleza, linaje y escritura genealógica en Castilla (siglos XIII-XIv)». Hispania. Revista Española de Historia, 2015, vol. 75, n. ${ }^{\circ}$ 251, pp. 617-640. Sobre la caracterización del linaje medieval como una estructura de parentesco patrilineal, véanse Val Valdivieso, María Isabel del. «La solidaridad familiar en Vizcaya en el siglo XV». En Congreso de Estudios Históricos «Vizcaya en la Edad Media». San Sebastián: Eusko Ikaskuntza, 1986, pp. 333-337, en especial, p. 33; o LADERO QUESADA, Miguel Ángel. «Linajes, bandos y parcialidades en la vida política de las ciudades castellanas (siglos XIV y xv)». En Bandos y querellas dinásticas en España al final de la Edad Media. Actas del Coloquio celebrado en la Biblioteca Española de París los días 15 y 16 de mayo de 1987. París: Ministerio de Asuntos Exteriores, 1991, pp. 105-134, en especial, p. 110. Para una caracterización cognaticia del linaje, véanse Guerreau-Jalabert, Anita. «Parentesco». En Le Goff, Jacques y Schmitt, Jean-Claude (dirs.). Diccionario razonado del Occidente Medieval. Madrid: Akal, 2003, pp. 626-636; y, con una perspectiva análoga centrada en el caso portugués, Sottomayor-Pizarro, José Augusto de. «Linhagem e estruturas de parentesco». e-Spania. Revue Électronique d'Études Hispaniques Médiévales, 2011, vol. 11 [disponible en: https://e-spania.revues. org/20366]. Las relaciones de parentesco, particularmente entre la baja nobleza castellana, se corresponden a 
ARSENIO DACOSTA

Sin duda ha habido meritorios esfuerzos en este ámbito -lo que nos permite avanzar en la cuestión- como la matización que ofrecía Marie-Claude Gerbet de los dos sentidos del concepto de linaje nobiliario ${ }^{10}$, o la respetuosa crítica de Jack Goody al uso que hacían del término los medievalistas franceses ${ }^{11}$. Este campo de investigación está sujeto a un determinismo que es necesario superar; a ello apuntan los últimos trabajos sobre la génesis y evolución del concepto de linaje en la Península Ibérica, cuya genealogía ha sido esbozada ya por José Carlos Ribeiro Miranda ${ }^{12}$. Dada la cronología que nos hemos propuesto ahora, esta cuestión queda relegada por una perspectiva más densa a partir de la obra de un autor muy concreto: Lope García de Salazar.

Nuestro autor nació en 1399, primogénito del caballero Ochoa de Salazar. Llegado a la treintena sustituyó a su padre al frente de su linaje hasta convertirlo en uno de los más poderosos y ricos de Vizcaya. Conoció el periodo más convulso de este territorio, el de las luchas de bandos, participando activa y violentamente en muchas de ellas desde los 18 años, tal y como el mismo narra en su Libro de las buenas andanças e fortunas ${ }^{13}$. Activo señor feudal, oficial regio e incluso mercader ${ }^{14}$, Lope García de Salazar vivirá una larga vida que se trunca desde 1471, año en que es hecho prisionero por sus propios hijos. Su cautiverio dura hasta 1476 año en que fallece posiblemente envenenado ${ }^{15}$. En ese lapso de tiempo Lope se dedicará a escribir su Libro, mucho más que una reelaboración de su

un sistema mixto, con una "concepción del parentesco menos jerárquica, más bilateral» (BECEIRo PitA, Isabel y Córdoba de la Llave, Ricardo. Parentesco, poder y mentalidad. La nobleza castellana, siglos XII-XV. Madrid: Consejo Superior de Investigaciones Científicas, 1990, p. 38).

10 A saber, el sentido estricto expresado en la Segunda Partida (línea de sucesión de abuelo, padre e hijo varones), y un sentido más amplio (grupo de descendientes con un antepasado y solar común); veáse: $L a$ noblesse dans le Royaume de Castille. Étude sur ses structures sociales en Estrémadure (1454-1516). Paris: Publications de la Sorbonne, 1979, pp. 106-107.

11 Críticas que no quedaban resueltas en La evolución de la familia y del matrimonio en Europa. Barcelona: Herder, 1986, en especial, pp. 308-323. Sobre la aportación de Goody, véase: Guerreau-JaLABERT, Anita. «La Parenté dans l'Europe médiévale et moderne: à propos d'une synthèse récente». L'Homme, 1989, vol. 29, n. ${ }^{\circ} 110$, pp. 69-93.

12 Miranda, José Carlos Ribeiro. "O argumento da linhagem na literatura ibérica do séc. xiII". $e$ Spania. Revue Électronique d'Études Hispaniques Médiévales, 2011, vol. 11 [consultado el 22/01/2016; disponible en: http:/ e-spania.revues.org/20347]. Desde una perspectiva puramente historiográfica véase, también, PÉrez, "En torno a las estructuras de parentesco de la aristocracia castellanoleonesa». Para el ámbito extrapeninsular, véase: Crouch, David. «The Historian, Lineage and Heraldry, 1050-1250». En: Coss, Peter y Keen, Maurice (eds.). Heraldry, Pageantry and Social Display in Medieval England. Woodbridge: Boydell, 2002, pp. 17-38.

13 En tercera persona, y con una pasmosa frialdad para nuestros parámetros, narra cómo él mismo mata en una emboscada a Lope Ochoa de Mendieta (Libro de las buenas andanças e fortunas, p. 869). En adelante, nos referiremos a esta obra como Libro. Para este trabajo seguimos la reciente edición crítica a cargo de Consuelo Villacorta (Bilbao: Universidad del País Vasco, 2015).

14 Las fuentes de renta del personaje se analizan in extenso en Aguirre Gandarias, Sabino. Lope García de Salazar. El primer historiador de Bizkaia (1399-1476). Bilbao: Diputación Foral de Bizkaia, 1994. Una revisión crítica en DAcosta, Arsenio. «Las fuentes de renta del linaje de Salazar: aportación al estudio de las haciendas nobiliarias en la corona de Castilla durante la Baja Edad Media». En DíAz De Durana, José Ramón y Reguera, Ińaki (eds.). Lope García de Salazar: banderizo y cronista. Portugalete: Ayuntamiento de Portugalete, 2002, pp. 41-64.

15 Es la hipótesis que defiende Aguirre Gandarias, Lope García de Salazar, pp. 251-263. 
ARSENIO DACOSTA

«PODEROSO EN PARIENTES E RENTAS»: CONCEPTOS, DISCURSOS Y PRÁCTICAS SOBRE EL LINAJE EN LOPE GARCÍA DE SALAZAR

anterior Crónica de Vizcaya, fechada en $1454^{16}$. Este último hecho incide en la propia motivación que expone el autor en el prólogo de su Libro:

oviendo mucho a voluntad de saber e de oír de los tales fechos, desde mi mocedad fasta aquí me trabaxé de aver libros e estorias de los fechos del mundo, faziéndolos buscar por las provincias e casas de los reyes e príncipes cristianos de allende la mar e de aquende por mis despensas con mercaderes e mareantes e por mí mesmo a esta parte e, a plazer de Nuestro Seńor, alcancé de todos ellos lo que obe en memoria, por lo cual, de todos ellos e de la memoria de los antepasados e de las oídas e vistas mías e, obrando sobre mí la fortuna, estando preso en la mi casa de Sant Martín de los que yo engendré e crié e acrecentée ${ }^{17}$.

Regido por un código que se resume en la fórmula del «más valer», la obra de Lope García de Salazar permitió a Julio Caro Baroja reclamar en 1956 una «teoría del linaje», al menos para los territorios vascos ${ }^{18}$. Volveremos sobre este punto.

El término linaje tiene en la baja Edad Media variadas acepciones ${ }^{19}$. Nuestro autor utiliza tres de esos significados a partir de fuentes variadas, pero siempre reelaborándolos según su particular sensibilidad e interés ${ }^{20}$. El primero es el del «humanal linaje», con conexiones expresas a la mitología y la historiografía clásicas ${ }^{21}$, pero también con un evidente sentido cristológico que conecta a García de Salazar con, por ejemplo, los Castigos e documentos de Sancho IV ${ }^{22}$. Sea cual sea el matiz, esta primera acepción remite a la «humana vertud», a la naturaleza humana expresada en el emocionante panegírico de Agamenón a la muerte de Aquiles:

Arquiles, a todo el mundo sostobieras por enemigo, mas matote la lanza del amor, lazo de todo el humanal linaje, el cual regestir no vale lança ni espada. E liose el amor con las falsedades troyanas e salió glorioso e vencedor, robando el despojo de la proeza del mundo ${ }^{23}$.

A quienes conocen el transcurso vital de Lope García de Salazar no deja de sorprenderles estos arrebatos de sensibilidad que trascienden las condiciones de la hipertextualidad de sus dos obras. Más allá de la genealogía y de la competencia internobiliar, merece la pena explorar ese conocimiento en otros ámbitos, por ejemplo,

16 Para este texto, que citaremos como Crónica en adelante, solo conocemos una edición, la de Sabino Aguirre Gandarias incluida en su Las dos primeras crónicas de Vizcaya. Estudios, textos críticos y apéndices. Bilbao: Caja de Ahorros Vizcaína, 1986, pp. 13-106, incluyendo introducción y útiles índices.

17 Libro, pp. 5-6.

18 Linajes y bandos. A propósito de la nueva edición de "Las Bienandanzas e Fortunas». Bilbao: Diputación Foral de Vizcaya, 1956.

19 Martín Alonso Pedraz documenta nueve acepciones distintas de la voz "linaje" (Diccionario medieval español. Desde las Glosas Emilianenses y Silenses (s. X) hasta el siglo XV. Salamanca: Universidad Pontificia de Salamanca, 1986).

20 Villacorta, Libro de las buenas andanças e fortunas, p. XXVI.

21 En alusión a los orígenes mitológicos de la Humanidad narrada por «los estoriadores» como Orosio (Libro, p. 22) o en referencia a la citada muerte de Aquiles (Libro, p. 129).

22 Capt. VIII. Cito por la edición de Bizzarri, Hugo O. Castigos del rey don Sancho IV. Frankfurt am Main-Madrid: Vervuert-Iberoamericana, 2001, p. 116.

23 Libro, p. 129. 
ARSENIO DACOSTA

el de los afectos y desafectos en el seno del linaje, esa cara oculta de la historia social de la nobleza.

También en el Libro de las buenas andanças e fortunas localizamos una segunda acepción de linaje como "estirpe» o "raza», tanto o más extendida que la anterior en la baja Edad Media castellana ${ }^{24}$. Así, Lope García alude al «linaje de los macabeos» o al de los godos ${ }^{25}$. Este último será un topos de legitimidad linajística para la nobleza peninsular hasta alcanzar, en los siglos XVI y XVII, un sesgo mitómano sobre el que ironizan los versos del Caballero del Febo cuando se refieren a don Quijote como "godo».

Aquí nos habremos de ocupar de la tercera acepción que hallamos en su Crónica de Vizcaya cuando trata de "los linajes de los solares que d'ellos suscedieron en esta montańa ${ }^{26}$, y también en su aludido Libro refiriéndose a "las casas e linajes antigos de Castilla e de otros de la sangre real» ${ }^{27}$.

Las obras de Lope García de Salazar no son las únicas en la Castilla del Cuatrocientos en situar al linaje en la centralidad del discurso nobiliario ${ }^{28}$. Sin embargo, en nuestro autor la noción de linaje va más allá de sus intereses sociales, erigiendo, como señalábamos antes, una particular concepción de la sociedad. Dejando de momento esta cuestión, la idea de linaje estructura expresamente su Crónica de Vizcaya. Tal y como señaló en su día Aguirre Gandarias este texto es organizado por García de Salazar a partir de la particularización y jerarquización de linajes «hasta desembocar en su persona, matrimonio e hijos» ${ }^{29}$. En la cúspide de la sucesión de linajes sitúa al más antiguo y prestigioso, el de los Haro, señores de Vizcaya, descendiendo por los linajes «que son los principales del señorío e condado de Viscaya e de las Encartaçiones»" ${ }^{30}$. En el Libro de las buenas andanças e fortunas el plan varía sustancialmente porque la ambición del autor es mayor y se lanza a construir una historia universal «a imagen y semejanza de las crónicas de las que se había nutrido» a juicio de Consuelo Villacorta ${ }^{31}$. No obstante, el trabajo desarrollado en la Crónica se recupera y amplía, cierto es que con algunas significativas modificaciones que solo incidentalmente comentaremos aquí. Con un mismo sentido de jerarquía, dedica una parte importante de su obra mayor a la descripción de los principales linajes de

24 Aparece en multitud de textos de toda naturaleza, y no es muy distinto del que hacen don Juan Manuel o Alfonso Álvarez de Villasandino del «linage de Agar» en la Crónica abreviada y en A los amores de una mora respectivamente (consulta realizada al CORDE de la Real Academia Espańola). Sobre este tipo de tratamientos textuales, véase Carrasco Manchado, Ana Isabel. «Nuevas herramientas para la historia de la Edad Media hispánica: los corpus textuales informatizados». En la España Medieval, 2011, vol. 34, pp. 343-372.

25 Libro, pp. 52 y 746 , respectivamente.

26 Crónica, p. 33.

27 Libro, p. 8.

28 Heusch, Carlos. «La pluma al servicio del linaje. El desarrollo de los nobiliarios en la Castilla Trastámara». e-Spania. Revue Électronique d'Études Hispaniques Médiévales et Modernes, 2011, vol. 11 [disponible en: https://e-spania.revues.org/20313]; y DAcosta, Arsenio. "A propósito de un aparente silencio: la memoria genealógica escrita de la nobleza peninsular en la baja Edad Media». Tiempos Modernos, 2016 , vol. 32 (en prensa).

29 Las dos primeras crónicas, p. 28.

30 Crónica, p. 33.

31 VillacorTa, Libro de las buenas andanças e fortunas, p. XXXV. 
ARSENIO DACOSTA

«PODEROSO EN PARIENTES E RENTAS»: CONCEPTOS, DISCURSOS Y PRÁCTICAS SOBRE EL LINAJE EN LOPE GARCÍA DE SALAZAR

Castilla comenzando de nuevo por el de los Haro (libro XX) y terminando por los de Vizcaya y territorios vecinos (libro XXI). Lope García expone abiertamente este plan a sus potenciales lectores: «lo cual todo esto fallarán más complidamente en los títulos de las generaciones de los dichos linages ${ }^{32}$.

En referencia a nuestro objetivo, la tercera acepción del término linaje, veamos si se percibe en un mismo y unívoco concepto subyacente, y cómo dicho concepto revela la naturaleza del poder de la nobleza castellana del siglo Xv.

\section{LA INCORPORACIÓN}

En la teoría del habitus ocupa un lugar central la noción del cuerpo o, mejor, la in-corporación de las prácticas, símbolos y valores sociales ${ }^{33}$. En el siglo Xv, como hoy -aunque el transhumanismo anuncie cambios al respecto-, vivimos socialmente a través de nuestros cuerpos ${ }^{34}$. No faltan alusiones al respecto en las obras de Lope García de Salazar, pero la más expresiva -ya que se refiere a sí mismo- la encontramos en su Crónica:

Este Lope García, seyendo con esta doña Joana Ibañes, fiso la casa de Sant Martín con todos sus edificios, e derribó todo lo primero, e fiso a medida de su altor las puertas que son en la sala de la torre mayor, por donde salen a las salas de fuera, porque los que d'él venieren sepan el altor que era su cuerpo ${ }^{35}$.

La anécdota, que no pasó a su Libro, es reveladora del sentido pedagógico de las palabras y acciones de los nobles de su época, conectando mente y cuerpo en relación al pasado y al futuro. Así se revela en otro expresivo fragmento del Libro:

Este Ladrón de Leiba, eredando aquella casa, afogó a su muger, porque se dezía ser mala de su cuerpo. E después fue preso e tomado todo lo suyo por Juan de Leiba, su fijo, deziendo que era fuera de su memoria ${ }^{36}$.

El universo del autor está fraguado con cuerpos y memorias que pertenecen y construyen simultáneamente su particular campo de comprensión social. Ello incluye el cuerpo femenino, como muestra el ejemplo anterior, siempre subalterno porque está socializado y es vector de socialización. Así se muestra en otros muchos ejemplos extraídos nuestro autor, donde una característica física e individual se convierte en marca identitaria de todo un linaje:

32 Libro, p. 941.

33 Sobre esto, véase Capdevielle, Julieta. «El concepto de habitus: “con Bourdieu y contra Bourdieu"». Anduli. Revista Andaluza de Ciencias Sociales, 2011, vol. 10, pp. 31-45, en especial, pp. 36 y ss.

34 Tomamos la expresión de Kuper, Adam. Cultura. La versión de los antropólogos. Barcelona: Paidós, 2001, p. 283. Un planteamiento teórico de la cuestión del cuerpo desde la perspectiva de la antropología histórica en Wulf, Christoph. Antropología. Historia, cultura, filosofía. Barcelona: Anthropos, 2008, pp. 159 y ss.

35 Crónica, p. 89.

36 Libro, p. 713. 
ARSENIO DACOSTA

E a don Sancho Peres fuendo çeco, físolo caballero el rey de Aragón, e preguntó le cómo le llamaban al moço en su tierra de bascuençe, e él respondióle que motila, e por esto llamaron a él e a su hermano e a todo su linaje los Motilas ${ }^{37}$.

No extrañe que, en la definición de linaje nobiliario, el cuerpo adquiera estatuto de metáfora principal, ora con sesgos naturalistas, ora reflejo lejano de las teorías organicistas medievales, ora como símbolo político. En el primero de los sentidos, puede traerse a colación un pasaje tomado casi literalmente del Libro del linaje de los Señores de Ayala, de Fernán Pérez de Ayala ${ }^{38}$ :

Este don Sant García que tomó el cargo de la casa de Ayala llamaron el Caveçudo, deziendo que la avía grande e otros que la avía buena; pero dízese que lo avía todo ${ }^{39}$.

La cabeza es el último reducto de vida del hombre, y también metáfora de las capacidades y expectativas trazadas en torno al jefe del linaje, no casualmente definido a través de otra metáfora complementaria, la de "rodilla ${ }^{40}$, que en el imaginario genealógico -también jerarquizado- define la filiación:

En esta batalla era alferze del infante don Sancho don Álvaro de Oca, fijo de don Álvaro Díaz de Oca, que, toviendo su vandera, le mataron el cavallo e, cayendo en tierra, se levantó e tomó la vandera e levantola e fincola en la tierra. E estando con ella, le cortaron las manos en que la tenía e apretola con los braços; e cortándole aquello, le travó con los dientes e llamando Castilla e Oca le cortaron la cabeça. E cuando contavan estas nuevas ant'el rey, dixo aquel Álvar Díaz, que era ya viejo, que estava allí: «Agora sé yo que mi muger era buena, que aquel su fijo de mi rodilla salió». E no mostró otro pesar por su muerte e esto le fue mucho loado a él ${ }^{41}$.

El cuerpo es, pues, el primer medio de enculturación dentro del linaje. Uno de los más expresivos ejemplos que hallamos en Lope García de Salazar se refiere a la ejecución del hidalgo Juan López de San Pelayo de Mena por orden de Pedro Fernández de Velasco:

E oídas estas palabras, entristició mucho e fue un rato callando e llorando e, aun llorando, que dixo algunos de los suyos que no se devía fazer tal fecho e que se catase otra manera e que se llegaron todos sobre él diziéndole muchas palabras que lo acavase, si no, que ellos lo acavarían luego con sus manos e se desnaturarían d'él si luego no le empozase. E diéronle dos clerigos, a él uno e al fijo otro, e empozaron al fijo delante, por le dar mayor pesar; e empozaron a él, no lo dexando bien confesar los enemigos, e echáronlo al pozo del río. E tan esforçado se mostró e su cara alegre e su color no mudada como si estoviera en sus solazes, como solía. E así echado

37 Crónica, p. 60.

38 Dacosta, Arsenio (ed.). El "Libro del linaje de los señores de Ayala» y otros textos genealógicos. Materiales para el estudio de la conciencia del linaje en la Baja Edad Media. Bilbao: Universidad del País Vasco, 2007, p. 139.

39 Libro, p. 708.

40 El término equivalente en euskera, «belaun», identifica de forma genérica los grados de parentesco y para CARo Baroja expresa «una idea de juntura, intersección» (Linajes y bandos, p. 14, nota 15).

41 Libro, pp. 535-536. 
ARSENIO DACOSTA

«PODEROSO EN PARIENTES E RENTAS»: CONCEPTOS, DISCURSOS Y PRÁCTICAS SOBRE EL LINAJE

EN LOPE GARCÍA DE SALAZAR

en el agua, que era asaz pequeńa que dava de los pies en el suelo e que salía arriba la caveça sobre el agua e que le davan los enemigos con los cuentos de las lanças, e aun algunos con los fierros, e que les dezía cada vez que así salía: «Dad, dad, fijos de putas, que, como tengo una alma e un cuerpo que toviese ciento, no vos podríades vengar de mí, que yo he seído en sacar tanta sangre de vuestro linaje que no lo podríades vengar en otros trecientos tales como yo, e dad cuanto podierdes». E así lo fizieron morir penadamente ${ }^{42}$.

Como en otros pasajes de la obra mayor de nuestro autor, la crueldad es descrita con gran naturalismo y con un fin abiertamente didáctico. Más allá de la intención desprestigiante que se detecta en la caracterización del Velasco, enemigo del cronista, el fragmento permite comprender el linaje a través del cuerpo, de sus gestos y de las emociones que transmiten ${ }^{43}$. Unas emociones que deben ser sometidas - «su cara alegre e su color no mudada» - en aras de una actitud ejemplarizante: dentro de la lógica del «valer más», Juan López de San Pelayo sólo puede encontrar consuelo en su particular contabilidad de la venganza. Ya sea en la literalidad de la anécdota anterior - -en sacar tanta sangre de vuestro linaje»-, como en sus más extensas formas metafóricas, la sangre ocupa un lugar central en los discursos sobre la nobleza en la Castilla bajomedieval tal y como ha destacado recientemente Teófilo F. Ruiz ${ }^{44}$. Dicho en palabras de Lope García de Salazar:

cuanto más que bienen antiguamente de tan noble sangre e limpia de los reyes e señores, donde estos linajes susodichos venimos ${ }^{45}$.

En el caso de un nutrido grupo de linajes cantábricos ${ }^{46}$ Lope García de Salazar destaca la antigüedad de esa sangre:

42 Libro, p. 828.

43 Para esto remitimos a Schmitt, Jean-Claude. La raison des gestes dans l'Occident médiéval. Paris: Gallimard, 1990. Para la Castilla medieval y una perspectiva centrada en la historia social, véase BECEIRO PITA, Isabel. «El escrito, la palabra y el gesto en las tomas de posesión señoriales». Studia Historica. Historia Medieval, 1994, vol. 12, pp. 53-82.

44 Discursos de sangre y parentesco en Castilla durante la Baja Edad Media y la Época Moderna. Santander: Universidad de Cantabria, 2015; publicado originalmente como: «Discourses of Blood and Kinship in Late Medieval and Early Modern Castile». En Johnson, Christopher H. et álii (eds.). Blood and Kinship: Matter for Metaphor from Ancient Rome to the Present. Oxford: Berhahn Books, 2013, pp. 105-124. Para la identificación de los conceptos de «nobleza de sangre» $\mathrm{y}$ «linaje» que triunfa -no sin controversia- en el siglo XVI véase Hernández Franco, Juan. Sangre limpia, sangre española. El debate de los estatutos de limpieza (Siglos XV-XVII). Madrid: Cátedra, 2011.

45 Crónica, p. 34.

46 Entre ellos el de Velasco, el de Tovar y, por supuesto, el suyo propio. A este respecto Isabel BeCEIRO apunta como "curioso» el hecho de que la diferencia de estatus entre linajes como Velasco o Tovar y otros de nimia influencia como de La Cerca o Sarabia ( La conciencia de los antepasados y la gloria del linaje en la Castilla bajomedieval». En PAstor, Reyna (dir.). Relaciones de poder, de producción y de parentesco en la Edad Media y Moderna. Madrid: Consejo Superior de Investigaciones Científicas, 1990, p. 340). La equiparación que ofrece el motivo legendario puede obedecerse a cuestiones históricas, pero también a una pulsión prestigiante por parte de Lope García de Salazar, en pugna por la hegemonía regional con los Velasco y otros linajes. Para una perspectiva estamental de este tipo de narrativas en la obra de Lope García de Salazar y otros autores, DAcosta, Arsenio. «De la conciencia del linaje a la defensa estamental. Acerca de algunas narrativas nobiliarias vascas». Medievalista [en línea], 2010, vol. 8 [disponible en: http://www2.fcsh.unl.pt/iem/medievalista/MEDIEVALISTA8/dacosta8007.html]. 
ARSENIO DACOSTA

En el año del Nuestro Señor de DCCXL años, arribaron en Santońa, que es cavo Laredo, una grande flota de navíos con muchas gentes de godos de las islas d'Escancia, que venían en socorro de los godos d'Espańa, sopiendo el trabaxo en que estavan. E como de luengas tierras venían fatigados de la mar, ovieron mucho plazer cuando vieron la tierra e aquel monte de Santońa, dando gracias al Señor e a la Virgen Santa María e rogando a todos los santos, las rodillas fincadas, que rogasen por ellos; e por aquello llamaron e llaman aquel monte Santoña ${ }^{47}$.

Mayor antigüedad y también mayor calidad moral la de esos godos marinos: estirpe de fundadores de lugares y monasterios, estirpe extranjera y no contaminada por los vicios y pecados de los godos peninsulares, responsables últimos de la Pérdida de España.

\section{LA RACIONALIDAD}

La noción de habitus está ligada a la teoría de la acción en la que el comportamiento de los actores -o agentes- no se entiende en términos de racionalidad o irracionalidad, sino de «sentido práctico» ${ }^{48}$. Ningún aspecto de la vida de la nobleza, ni siquiera aquellos que pertenecen al ámbito de las creencias o de los símbolos, escapa a ese sentido de inexorable lógica contextual, orientada siempre a cimentar el poder del individuo o su linaje ${ }^{49}$. Un ejemplo que apunta directamente a ello lo encontramos en la caracterización jurídica de los muertos nobles y sus almas ${ }^{50}$.

Otra anécdota vital de Lope García de Salazar servirá para interpretar ese sentido práctico de las acciones personales y agendas colectivas en torno a la materialidad del poder del linaje. Como decíamos, en su vejez, y como consecuencia del conflicto surgido por la sucesión de su linaje, Lope García de Salazar es encerrado en su torre por aquellos de sus hijos que no aceptaban que la sucesión recayera en Ochoa, hijo de su primogénito fallecido ${ }^{51}$. Hasta cierto punto, esta defensa de la sucesión agnática contradice el pensa-

$47 \quad$ Libro, p. 456.

48 «Dirigir las investigaciones, tal como propone P. Bourdieu, hacia la búsqueda del sentido práctico o "usos sociales" que tiene el parentesco o el preferencial dentro de la estructura familiar del linaje» (HERNÁNDEZ Franco, Juan. "Consideraciones y propuestas sobre linaje y parentesco». En Familia, parentesco y linaje. Congreso Internacional Historia de la Familia: Nuevas perspectivas sobre la sociedad europea. Murcia: Universidad de Murcia, 1997, p. 28). Sobre la aludida noción, véase: Fernández FernándeZ, José Manuel. «Habitus y sentido práctico: la recuperación del agente en la obra de Bourdieu». Cuadernos de Trabajo Social, 2003, vol. 16, pp. 7-28.

49 Hernández Franco y Rodríguez Pérez hablan de una «lógica de las prácticas» («strategias, prácticas y actores», p. 27).

50 Así lo ha demostrado recientemente Maria de Lurdes Rosa para el Portugal del Cuatrocientos: As almas herdeiras. Fundaçâo de capelas fúnebres e afirmação da alma como sujeito de direito (Portugal, 1400-1521). Lisboa: Imprensa Nacional-Casa da Moeda, 2012. Otro ejemplo podemos hallarlo en el Fuero General de Navarra (II, 4, 5): "Cómo hereda fillo muerto á padre muerto» (cito por la edición de Pablo ILARregui y Segundo Lapuerta (Pamplona: Imprenta Provincial, 1869).

51 El primogénito Lope había muerto en 1462; poco después, en 1468, morirán otros dos hijos varones del cronista, Gonzalo y Fernando. Todos ellos habían dejado descendencia. La oposición a la sucesión planteada por Lope García la protagonizará su hijo Juan Moro. Véase Aguirre Gandarias, Lope García de Salazar, pp. 235 y ss. 
ARSENIO DACOSTA

«PODEROSO EN PARIENTES E RENTAS»: CONCEPTOS, DISCURSOS Y PRÁCTICAS SOBRE EL LINAJE

EN LOPE GARCÍA DE SALAZAR

miento del autor en lo que se refiere a lo que don Julio Caro Baroja describió como «teoría del linaje»; a ello habremos de referirnos, pero esta postura es totalmente coherente con la lógica defendida en toda su obra, en la que apuesta abiertamente por la concentración del patrimonio en el primogénito varón. El cronista se muestra contrario a la disgregación del patrimonio del linaje, siendo particularmente expresivo cuando alude al reparto de la herencia de Fernando I de Castilla ${ }^{52}$ o cuando, con evidente afán aleccionador, narra la historia de Ordoño de Zamudio el Viejo. Según Lope, bajo este personaje su linaje llega a la altura de «los otros solares mayores» ${ }^{53}$; sin embargo, la acción de este pariente mayor merece la mayor de las reprensiones en el Libro de las buenas andanças, ya que:

no catando al avaxamiento de su casa e linaje, partiolo todo en cuatro fijos e dos fijas, faziéndolo dos partes, como dicho es, por donde todos sus decendientes ovieron e han causa de se matar unos con otros e han seido e son sogetos a comer pan de algunos solares e casas comarcanas ${ }^{54}$.

Es evidente el paralelismo de este pasaje con la propia experiencia vital de Lope García de Salazar ${ }^{55}$. De hecho, será esta la razón de su reclusión forzosa. Es de advertir, sin embargo, que lo que estaba en juego no era tanto el cumplimiento de una determinada modalidad de herencia con vínculo, sino quién de entre los herederos posibles iba a ser el próximo líder del linaje. De hecho, el Fuero Viejo de Vizcaya -cuya conflictiva génesis conoció bien el cronista- no contiene una prescripción definida sobre la vinculación al primogénito, sino que refleja un sistema de herencia abierto que no solo no discrimina entre «fijos e fijas», sino que se ocupa de buscar mecanismos de herencia para los «fijos naturales»"

Volviendo a nuestro ejemplo, el solar de Salazar queda dividido como consecuencia de las profundas diferencias entre Juan Moro y su sobrino Ochoa, o justamente por lo contrario, esto es, la coincidencia de sus objetivos: ser cada uno de ellos el pariente mayor del linaje. Es aquí donde Lope García de Salazar fuerza un tanto el argumento en su propio beneficio. Como parece, Lope García se mira en el ejemplo de los Zamudio o de la casa real castellana para defender la pertinencia del mayorazgo, pero, por otro lado,

52 «Título de la muerte del virtuoso rey don Ferrando e de cómo partió sus reynos a sus fijos e del daño que dello vino a ellos» (Libro, p. 509).

53 «En rentas e posesiones e en parientes, e aun algún tanto más complido que algunos d'ellas» (Libro, p. 744).

54 Ibidem.

55 Refiriéndose a la fundación del mayorazgo en 1451, Sabino AguirRe dice: «él no podía consentir que algún día su propia herencia llegara a dividirse y así se debilitara hasta el punto que hubo de luchar tenazmente [...] por preservarla en su totalidad» (Lope García de Salazar, p. 197). Carlos MarTínez GorRIARÁN incide en lo mismo cuando dice que «se generaliza la práctica del mayorazgo, idónea para conservar la potencia de los linajes» (Casa, provincia, rey: para una historia de la cultura del poder en el País Vasco. Irún: Alberdania, 1993, p. 131).

56 Fuero Viejo, \#104. Efectivamente en este artículo se plantea la mejora de uno los «fijos o fijas» entregándole «todos sus bienes muebles e raýzes, dando e apartando algún tanto de tierra, poco o mucho, a los otros fijos e fijas» (citamos por Hidalgo DE Cisneros, Concepción et álii (eds.). Fuentes jurídicas medievales del Señorio de Vizcaya. Cuadernos Legales, Capitulos de la Hermandad y Fuero Viejo (1342-1506). San Sebastián: Eusko Ikaskuntza, 1986, p. 113). En un sentido similar se expresa el Fuero General de Navarra, II, 4, 4. 
ARSENIO DACOSTA

provoca el fracaso de la aludida «teoría»: el pariente mayor debe procurar por encima de cualquier otra cosa la supervivencia del linaje. Con su empeńo por primar la línea de su primogénito fallecido frente al ambicioso segundón Lope García de Salazar ponía a su linaje en el punto límite de ruptura. Una ruptura finalmente no materializada, pero que tuvo al anciano Lope como principal víctima.

La «teoría del linaje» en Lope García de Salazar -y en sus contemporáneos- no se concreta en el mayorazgo, sino en el «valer más»" ${ }^{57}$, un agonal concepto orientado a la acumulación y acrecentamiento del linaje:

Garci López, hermano de Miguel López [de Lazcano], pobló el solar de Iyarça de Guipúzcoa e acrecentolo mucho de rentas e de parientes ${ }^{58}$.

Ese «valer más», esa competencia, tiene una clara dimensión material, de acumulación de bienes y rentas de variada naturaleza y procedencia. No insistiremos aquí en este fundamento del poder del linaje por ser un aspecto razonablemente bien conocido para la nobleza peninsular, incluso para el grupo hidalgo de la Cornisa Cantábrica ${ }^{59}$. Tampoco podemos detenernos en la otra cara de la acumulación, esto es, en la lógica de la redistribución de la renta feudal que está en el corazón de la adscripción y acrecentamiento de parientes, pero también en la extensión de la competencia internobiliaria ${ }^{60}$. En la particular «teoría del linaje» de Lope García de Salazar este aspecto es crucial y en él juega un papel fundamental el "pariente mayor». En torno a él se formulaba lo que Julio Caro Baroja denominó «solidaridad agnática» que iba mucho más allá de un determinado modelo de filiación para expresar en realidad la naturaleza compleja, contextual y dinámica de las relaciones en el seno del linaje ${ }^{61}$. La obra de Lope García de Salazar está plagada de ejemplos que, en un sentido positivo o negativo, aluden a esa relación entre pariente mayor y deudo. Solo habremos de

57 ACHón InSAusti, José Ángel. "Valer más” o "valer igual”: estrategias banderizas y corporativas en la constitución de la provincia de Guipúzcoa». En El Pueblo Vasco en el Renacimiento (1491-1521). Bilbao: Mensajero, 1994, pp. 55-76; y DAcosta, Arsenio. Los linajes de Bizkaia en la Baja Edad Media: poder, parentesco y conflicto. Bilbao: Universidad del País Vasco, 2004, pp. 45-93.

58 Libro, p. 730.

59 Para el ámbito vasco de finales de la Edad Media hay algunos trabajos monográficos de entidad, por ejemplo: Vidal-Abarca, Juan. Los Herrán: historia y genealogía de una familia vasca. Vitoria: Diputación Foral de Álava, 1993; Achón Insausti, José Ángel. "A voz de concejo». Linaje y corporación urbana en la constitución de la Provincia de Gipuzkoa: los Báñez y Mondragón, siglos XIII-XVI. San Sebastián: Diputación Foral de Gipuzkoa, 1995; Marín Paredes, José Antonio. "Semejante Pariente Mayor». Parentesco, solar, comunidady linaje en la institución de un Pariente Mayor en Gipuzkoa: los señores del solar de Oñaz y Loyola (siglos XIV-XVI). San Sebastián: Diputación Foral de Gipuzkoa, 1998; García Fernández, Ernesto. «El linaje Avendaño: causas y consecuencias de su ascenso social en la Baja Edad Media». Anuario de Estudios Medievales, 2007, vol. 37, n. ${ }^{\circ}$ 2, pp. 527-561; y Munita Loinaz, José Antonio et álii. "En tiempo de ruidos e bandos»: nuevos textos para el estudio de los linajes vizcainos: los Barroeta de la merindad de Marquina (1355-1547). Bilbao: Universidad del País Vasco, 2014.

60 Véanse: Morsel, La aristocracia medieval, pp. 342 y ss., y SÁnchez León, Pablo. «Aspectos de una teoría de la competencia señorial: organización patrimonial, redistribución de recursos y cambio social». Hispania. Revista Española de Historia, 1993, vol. 53, n. ${ }^{\circ} 185$, pp. 885-905.

61 Linajes y bandos, en especial, pp. 29 y ss. 
ARSENIO DACOSTA

«PODEROSO EN PARIENTES E RENTAS»: CONCEPTOS, DISCURSOS Y PRÁCTICAS SOBRE EL LINAJE

EN LOPE GARCÍA DE SALAZAR

mencionar un caso que, por lo extraordinario de las circunstancias, es revelador de la naturaleza de estas relaciones.

En junio de 1448 se produce la batalla banderiza más impactante para los contemporáneos ${ }^{62}$. Lo más llamativo del caso no es tanto la dimensión del enfrentamiento, ni que la villa de Mondragón sea incendiada, sino que por primera vez se produce la muerte violenta de uno de los principales parientes mayores de estos territorios: Gómez González de Butrón. Lo que nos interesa destacar es la naturaleza contextual y fluida del poder del pariente mayor y de las redes de relaciones tejidas en torno al mismo. Así narra García de Salazar qué ocurre cuando este pariente mayor se ve cercado por el fuego y las tropas de los gamboínos:

Martín Roiz de Olaso, su yerno, por lo escapar de la muerte embiole dezir por una su carta con un moço en que saliese en la delantera por donde él e su gente estava e que le daría pasada. E como el moço topó con Lope de Unçueta, que iba en la delantera, como dicho es, para esperar en aquellas eramenteras e le preguntó por Gómez González e díxole que qué lo quería e díxole que traía una carta de Martín Roiz, su yerno, e dixo: «Dámela, que yo só». E tomola e leyola. E como vio que podía pasar seguro, no curando d'esperar allí, como lo avían concertado, fuese su camino por donde Martín Roiz le mandava e pasase con los que iban con él porque no le destorvó ninguno, cuidando que era Gómez González. E cuando llegó Gómez González aquellas casas e no falló a los suyos, viose perdido e tiró adelante e topó con los enemigos ${ }^{63}$.

El fragmento revela que, más allá de las adscripciones y enemistades banderizas, existía una suerte de solidaridad de clase entre los parientes mayores, cimentada en redes de alianza como la que une a Martín Ruiz de Olaso con su malogrado suegro. También pone en entredicho, como se ha dicho ya, la distancia existente entre los tópicos y la realidad de la fidelidad ${ }^{64}$. Una fidelidad que puede considerarse cimentada sobre el parentesco o sobre vínculos de vecindad u otros netamente feudales, aunque posiblemente lo sea en una combinación perfectamente coherente de todas ellas. A nuestro modo de ver, las relaciones sociales que se tejen en torno al pariente mayor, lo mismo que el poder que a este se atribuye o ejerce de forma efectiva no son fenómenos unidireccionales o monocausales. Tal y como señaló Michel Foucault, el poder «[no] es un fenómeno de dominación masiva y homogénea de un individuo sobre los otros.

62 Aparte de Lope García de Salazar, la recogen los anónimos Anales Breves de Vizcaya, \#271 y 272 (editados por Aguirre Gandarias, Las dos primeras crónicas, pp. 171-172); y, también, las famosas endechas del Cantar de Mondragón (editadas por Koldo Mitxelena en Textos arcaicos vascos. San Sebastián: Diputación Foral de Gipuzkoa-Universidad del País Vasco, 1990, pp. 81-88). Un análisis de este y otros cantares euskéricos desde la perspectiva aquí adoptada en: Díaz de Durana Ortiz de Urbina, José Ramón y Fernández de Larrea y Rojas, Jon Andoni. «El discurso político de los protagonistas de las luchas sociales en el País Vasco al final de la Edad Media». En Alfonso Antón, Isabel; Escalona Monge, Julio; Martin, Georges (coords.). Lucha politica: condena y legitimación en la España medieval. Lyon: ENS Éditions, 2004, pp. 313-336.

63 Libro, pp. 814-815.

64 Díaz de Durana Ortiz de Urbina, José Ramón; Dacosta, Arsenio. «La dimensión social del liderazgo del linaje: solidaridad, poder y violencia (País Vasco, siglo xv)». Studia Zamorensia, 2013, vol. 12, pp. 87-105. 
ARSENIO DACOSTA

[...] El poder tiene que ser analizado como algo que circula, o más bien, como algo que no funciona sino en cadena ${ }^{65}$, como vienen demostrando los estudios realizados a escala regional en el País Vasco ${ }^{66}$. La redistribución de la renta feudal y el cumplimiento de otras expectativas por parte del pariente mayor sostienen un precario mundo de fidelidad, adhesión y solidaridad.

\section{LA REPRODUCCIÓN}

El espacio entre la estructura y la acción, entre las representaciones y las prácticas caracterizan el campo de comprensión del linaje. Podríamos tomar como ejemplo la definición de filiación que ofrece la Segunda Partida (XXI, 2), según la cual el linaje se vincula a la sucesión continuada de generaciones por vía masculina. De forma similar la encontramos en Lope García de Salazar:

E de Vedia es agora el principal d'él Sancho Ortiz de Vedia, que se falla que aviene en siete generaciones del cavallero de Galdaño, que fue natural de Navarra e vino a poblar allí; e viene d'él de padre en padre ${ }^{67}$.

Sin embargo, la Cuarta Partida (VI, 2) ofrece una definición más genérica en alusión al «parentesco de linaje»:

Linea de parentesco, es ayuntamiento ordenado de personas, que se tienen vnas a otras, como cadena, descendiendo de una rayz; et fazen entre si grados departidos ${ }^{68}$.

Alfonso X buscaba definir y ordenar la realidad, también en el ámbito de las relaciones de parentesco a las que dedica la Cuarta Partida ${ }^{69}$. Algo de ello vemos reflejado en las obras de Lope García de Salazar, donde encontramos esa tensión entre la lógica patrilineal y las estrategias que surgen de la filiación y, sobre todo, de la alianza. El concepto de agnatismo se mueve en una lógica que no necesita afirmación, que se retroalimenta en su veracidad:

65 Un diálogo sobre el poder y otras conversaciones. Madrid: Alianza Editorial, 1981, pp. 142-143.

66 Ramírez Vaquero, Eloísa. Solidaridades nobiliarias y conflictos políticos en Navarra, 1387-1464. Pamplona: Gobierno de Navarra, 1990; y Dacosta, Los linajes de Bizkaia.

67 Libro, p. 737.

68 Citamos por la edición de Madrid: Compañía General de Impresores y Libreros del Reino, 1843, pp. 502-503.

69 Martin, Georges. "Control regio de la violencia nobiliaria. La caballería según Alfonso X de Castilla (comentario al título XXI de la Segunda partida)». En Alfonso Antón, Escalona Monge y MarTIN (coords), Lucha política: condena y legitimación en la España medieval, pp. 219-234. En el ámbito del "parentesco», véase el magnífico análisis de Simon Teuscher en el que se demuestra cómo el poder político influye decisivamente en la organización de las familias de la élite ( Politics of Kinship in the City of Bern at the End of the Middle Ages». En Warren, David; Teuscher, Simon y Mathieu, Jon (eds.). Kinship in Europe: Approaches to Long-Term Development (1300-1900). New York-Oxford: Berghahn Books, 2007, pp. 76-90). 
ARSENIO DACOSTA

«PODEROSO EN PARIENTES E RENTAS»: CONCEPTOS, DISCURSOS Y PRÁCTICAS SOBRE EL LINAJE

EN LOPE GARCÍA DE SALAZAR

Del linaje e línea derecha de Laín Calvo, que fue uno de los dos allcaldes e regidores que los castellanos posieron por quien fuessen jusgados e regidos, [vienen] el Cide Rui Días de Vibar, los de Haro e los de Mendoça por los de Castro $^{70}$.

La perfección formal del arquetipo, en palabras de Julio Caro Baroja ${ }^{71}$, es lo que permite sostener la verosimilitud de una leyenda como la que nos transmite Lope García de Salazar sobre la descendencia de Laín Calvo por vía masculina, por «línea derecha». Un arquetipo que se confronta con la terca realidad social, definida por espacios menos perfilados que los narrativos. Un ámbito donde esto se percibe con nitidez lo hallamos en el tratamiento que hace Lope García de Salazar de la descendencia ilegítima del pariente mayor de linaje. En primer lugar, porque no son pocos los linajes que nacen de una relación informal, comenzando por el oscuro origen del primer señor de Vizcaya, Jaun Zuria:

E que estando allí que durmió con ella en sueñas un diablo, que llaman en Viscaya el Culuebro Señor de Casa, e qu'él empreñó. E d'estas dos cosas no se sabe cuál d'ellas fue más cierta, pero como quiera que fue, la infanta fue preñada, e parió un fijo que fue ome mucho fermoso e de buen cuerpo, e llamáronle don Çuría, que quiere desir en bascuence don Blanco ${ }^{72}$.

A pesar del valor dado por Lope García a la primogenitura masculina legítima, la situación de bastardía no es desprestigiante, ya que afecta a otros muchos linajes ${ }^{73}$, incluido el suyo propio:

Contado ha la istoria cómo Lope García de Salazar ovo ciento e XX fijos e fijas, entre los cuales fue el primero engendrado Juan López de Salazar, que lo ovo este su padre en una moça en Nograro seyendo mancevo de XV ańos $^{74}$.

La nada inocente narrativa sobre su ancestro homónimo es recordada en bastantes ocasiones por nuestro cronista; su voluntad es obvia: más allá de la proyección de poder sexual sobre sus descendientes, la estrategia del pariente mayor es abiertamente reproductiva, en un sentido netamente social:

e los fijos vastardos de Lope García [de Salazar] derramáronse por todo el regno, por donde su linaje es oy esparsido por muchos regnos e provincias ${ }^{75}$.

70 Crónica, p. 50.

71 Caro Baroja, Julio. De arquetipos y leyendas. Dos tratados introductorios. Madrid: Círculo de Lectores, 1989 , p. 100 .

72 Crónica, p. 35.

73 Para las narrativas de linajes cantábricos este asunto de la bastardía es tratado con detalle en DACOsTA, Arsenio. «De dónde sucedieron unos en otros. La historia y el parentesco vistos por los linajes vizcaínos bajomedievales». Vasconia, 1999, vol. 28, pp. 61 y ss.

74 Libro, p. 756.

75 Crónica, p. 74. 
ARSENIO DACOSTA

Por ello parece lógico que nuestro autor se refiera a esta descendencia como «fijos de ganançia» en numerosas ocasiones ${ }^{76}$. Esta definición de la bastardía ${ }^{77}$ apunta hacia el terreno de las estrategias de reproducción del linaje, donde todos los individuos, sea cual sea su género, están en disposición de contribuir.

Eso no significa que en torno a la reproducción del linaje no se vayan concretando tendencias en conflicto. De un lado, la lógica de la alianza, exogámica en esta latitud y cronología, pero al mismo tiempo jerarquizada. De otro, la tensión que produce la tendencia a sustituir la bilateralidad del sistema de herencia por una alternativa de concentración a favor del primogénito varón. En relación a lo primero, esto es lo que narra respecto de uno de sus abuelos:

Juan Sánchez, el fijo mayor legítimo d'este Juan López de Salazar, fue mucho valiente y esforçado. E casó con doña María Sánchez, fija de Furtud Sánchez de Çamudio de Susunaga, e ganó mucha fazienda, toviendo por tutoría las rentas del solar de Muñatones por doña Teresa, su muger, que fue fija de Ochoa de Muńatones, e compró grandes eredamientos en Castro e su término ${ }^{78}$.

La elección de matrimonios ventajosos en un mercado matrimonial cada vez más cerrado revela que el linaje es reflejo de un estamento fuertemente jerarquizado. Esta jerarquización se manifiesta en la persecución de ventajas competitivas a través de estrategias que, como las de alianza, pueden verse frustradas, pero que son inevitables en el proceso de reproducción social ${ }^{79}$. Cierto es que, en ocasiones, los matrimonios se desarrollan según la voluntad de los contrayentes, incluyendo la voluntad de ciertas damas -en clara remembranza de los amores prohibidos de la troyana Briseida ${ }^{80}-$, pero lo normal es que obedezcan a calculadas estrategias de linaje.

En cuanto a lo segundo, la tendencia a transmitir el poder y el patrimonio al primogénito varón, es uno de los argumentos que sirven retrospectivamente a caracterizar los orígenes del linaje. Una de las narrativas más interesantes en Lope revela una lógica bien distinta:

E este don García Gallindis, cuando yasía a la muerte, llamó a sus fijos e mandólos que todos tres partiesen su herencia en igual grado, e asimismo mandó a doña Alverta Sanches

76 Solo en la Crónica, utiliza el término en pp. 47, 59, 63, 64, 66, 69, 71, 72, 76, 79, 81, 83, 84 y 86.

77 La Cuarta Partida (XIV, 1) ofrece una etimología diferente para la expresión "ganancia»: «quieren tanto decir como ganancia que es hecha fuera de mandamiento de la iglesia» (sobre los hijos ilegítimos: Ibidem, XV, 1). El término "fijos de ganancia» ya se encuentra en algunos fueros navarros contemporáneos, determinando igualdad de derechos de herencia (Ramos y Loscertales, José M.a (ed.). Fuero de Viguera y Val de Funes. Salamanca: Universidad de Salamanca, 1956, \#385, p. 71). En el Fuero General de Navarra se distingue nítidamente entre el hijo "en adulterio nascido" y el «fijo de ganancia», estando el primero desprovisto de todo derecho de herencia (cf. Ibidem, IV, 3, 13 y IV, 4, 1).

78 Libro, p. 756.

79 Bourdieu, Pierre. «Les stratégies matrimoniales dans le système de reproduction». Annales. Économies, Sociétés, Civilisations, 1972, vol. 27, pp. 1105-1125.

80 Ibidem, p. 119. Ciertamente, los casos no son abundantes, pero tampoco raros; véase, por ejemplo, los referidos a Teresa de Muńatones o Isabel de Salcedo, ambas casadas contra la voluntad de sus progenitores (Ibidem, pp. 751 y 756 , respectivamente). 
ARSENIO DACOSTA

«PODEROSO EN PARIENTES E RENTAS»: CONCEPTOS, DISCURSOS Y PRÁCTICAS SOBRE EL LINAJE

EN LOPE GARCÍA DE SALAZAR

que partiesse a Orosco, que ella avía heredado de su padre don Sancho García de Çurbano. E don Pero García que era el mayor, dixo que non quería tomar el cargo de los parientes del solar, para no aver más de la tercia parte de la herencia. E dixo don Sancho García que si a él non le pesasse e su padre ge lo mandasse, que tomaría el cargo del solar, aunque non oviesse más de la tercia parte de la herencia. E el don Pero García dixo que le plasía, e el padre diógelo, desiendo que le daba con ello su vendición, e ovo don Sancho García el mayorasgo con la tercia parte de la herencia. E murió don García Gallindis e doña Alverta Sanches, e yasen en Quexana ${ }^{81}$.

Nos hemos propuesto no entrar en la cuestión del patrimonio vinculado, y tampoco entraremos en la caracterización del mayorazgo en el siglo xv, lejos aún del protagonismo que alcanzará en las centurias siguientes ${ }^{82}$. Sin embargo, el fragmento anterior sirve para ilustrar una cuestión clave en las estrategias de reproducción social del linaje: el cumplimiento de expectativas por parte del líder. Y es que el pariente mayor, incluso aunque fuera el beneficiario principal del patrimonio del linaje, «debía atender, de algún modo, a esas expectativas de disfrute patrimonial de los parientes próximos», tal y como señala M. ${ }^{a}$ Concepción Quintanilla Raso ${ }^{83}$. Mecanismos como la dote, que están en el corazón de los delicados equilibrios de alianza de los linajes, revelan, según Bourdieu, el alcance de dichas expectativas ${ }^{84}$. Volvemos, pues, a la consideración de que el linaje es, ante todo, una realidad socialmente construida sobre disposiciones contingentes y duraderas ${ }^{85}$.

\section{LA REPRESENTACIÓN}

Uno de los aspectos cruciales de la teoría bourdieusiana sobre el habitus es la consideración de que este se representa en variados mecanismos de percepción y acción ${ }^{86}$. Entre ellos el más importante posiblemente sea el capital simbólico ${ }^{87}$. Hemos visto ya cómo funcionaban algunos mitemas y metáforas alrededor de la noción de linaje. Otros más contribuyen a la idea de que el linaje, en la baja Edad Media al menos, conforma

81 Crónica, pp. 56-57. Lope García de Salazar la toma del Libro del linaje de Fernán Pérez de Ayala (DAcosta, El «Libro del linaje de los señores de Ayala», pp. 139-140).

82 Desde la perspectiva que aquí hemos tomado, el mejor trabajo de referencia sobre esta cuestión es el de Rosa, Maria de Lurdes. O Morgadio em Portugal, sécs. XIV-XV. Modelos e práticas de comportamento linhagístico. Lisboa: Editorial Estampa, 1995. Para Castilla, siguen siendo de referencia las reflexiones contenidas en Gerbet, Marie-Claude. «Majorat, stratégie familiale et pouvoir royal en Castille d'après quelques exemples pris en Extrémadure à la fin du Moyen Âge». En Les Espagnes médiévales. Aspects économiques et sociaux. Mélanges offerts à Jean Gautier Dalché. Nice: Les Belles Lettres-Université de Nice, 1983, pp. 257-276.

${ }_{83}$ «Propiedad vinculada y enajenaciones. Métodos y lógicas nobiliarias en la Castilla tardomedieval». Historia. Instituciones. Documentos, 2004, vol. 31, p. 500.

84 Ya lo abordó de forma general Bourdieu, «Les stratégies matrimoniales»; oportunamente citado por Marín Paredes, «Semejante Pariente Mayor». Parentesco, solar, comunidad y linaje, p. 160.

85 Bourdieu, Le sens pratique, p. 88.

86 Bourdieu, Le sens pratique, p. 91.

87 Bourdieu, Pierre. «Capital symbolique et classes sociales». L'Arc, 1978, vol. 72, pp. 13-19. 
ARSENIO DACOSTA

una suerte de capital colectivo para la nobleza. Tomemos, para ello, las nociones de solar y casa, recurrentes en la obra de Lope García de Salazar ${ }^{88}$.

El significado de solar siempre apunta hacia una identidad social y colectiva:

E d'este linaje de Achuriaga ay muchos d'este linaje, que son en aquel solar e linaje ${ }^{89}$.

Sin embargo, incluso cuando aparece como lema coordinado junto con el de linaje, encontramos que solar remite a un ámbito donde la materialidad y la metáfora se funden con naturalidad:

El solar e linaje d'Estrada el primero que la fundó e fizo la casa d'Estrada fue Diego Duque, que era fijo de un fijo vastardo de un rey de León, que dexó fijo eredero de la casa d'Estrada a Gonzalo d'Estrada, que eredó el dicho solar d'Estrada, que es cavo la villa de Sant Vicente de la Varquera ${ }^{90}$.

Efectivamente, la idea de linaje es inseparable del espacio físico donde reside el pariente mayor, espacio que es, redundantemente, prueba material del hecho fundacional. El solar identifica a los antepasados con el linaje, al conjunto de parientes que encuentra en ese lugar el referente de origen y que, no pocas veces, coincide con el apellido epónimo. Sin embargo, la noción de casa trasciende la materialidad de la torre familiar y sus anexos para connotar la posesión de una serie de derechos y su administración en los términos en los que Otto Brunner definía el oikos de la nobleza feudal ${ }^{91}$.

La noción de casa supera a la de linaje, abarcándola. En el xv se vincula invariablemente a la idea de señorío tal y como han señalado Beceiro y Córdoba ${ }^{92}$. Aparte de las casas reales y otras asimilables, Lope García restringe el uso de esta noción a aquellos linajes detentadores de señoríos, tuvieran o no la consideración de nobleza titulada:

Tres casas principales ovo en Castilla, que fueron levantadas en el tienpo que los condes de Castilla ovieron el seńorío por sí, porque d'ellos suscedieron los reyes de Castilla e de Portogal, de las cuales fueron la casa e señorío de Viscaya e la casa de Lara e la casa de Castro ${ }^{93}$.

88 Ángeles Líbano y Consuelo Villacorta han realizado una primera tentativa en «Aproximación léxica a las estructuras y grupos sociales en el espacio geográfico vascongado (siglos Xv y xvI)». Revista de Investigación Lingüistica, 2008, vol. 11, pp. 165-188.

89 Libro, p. 763.

90 Libro, p. 784.

91 Brunner, Otto. «La "casa grande” y la "Oeconomica” de la vieja Europa». Prismas. Revista de Historia Intelectual, 2010, vol. 14, pp. 117-136. Este trabajo se publicó originalmente en 1956. Disponible en: http://www.redalyc.org/pdf/3870/387036810001.pdf. Un análisis reciente que aborda esta perspectiva en MuÑoz Gómez, Víctor. "Domésticos, “casa”, y "afinidad” en la Castilla bajomedieval. ¿Una historia sin registros?». Mélanges de la Casa de Velázquez, 2015, vol. 45, n. 2 2, pp. 15-32. Aunque sale de nuestro periodo, sigue siendo de referencia para estas cuestiones Atienza Hernández, Ignacio. «Teoría y administración de la casa, linaje, familia extensa, ciclo vital y aristocracia en Castilla (s. XVI-XIX)». En Chacón Jiménez, Francisco; Hernández Franco, Juan y Peñafiel Ramón, Antonio (coords.). Familia, grupos sociales y mujer en España (s. XV-XIX). Murcia: Universidad de Murcia, 1991, pp. 13-48. Para el ámbito vasco, remito a la valiosa aportación de Achón Insausti, José Ángel. «Los parientes mayores». Iura Vasconiae, 2006, vol. 3, pp. 221-247.

92 Parentesco, poder y mentalidad, p. 89.

93 Crónica, p. 50. 
ARSENIO DACOSTA

«PODEROSO EN PARIENTES E RENTAS»: CONCEPTOS, DISCURSOS Y PRÁCTICAS SOBRE EL LINAJE

EN LOPE GARCÍA DE SALAZAR

Actualizando la nómina de casas a su tiempo, aunque omitiendo expresamente a los advenedizos ${ }^{94}$, el cronista habla de la casa de los Osorio, "la más antigua de Castilla e de León»" ${ }^{95}$, de otras triunfantes en época trastámara como Velasco, Estúninga, Leiba, Manrique, Guzmán, Rojas, Sandoval ${ }^{96}$, Avellaneda, Arellano, de la Vega, Padilla, Tovar, Quiñones, Pimentel, y muchas otras ${ }^{97}$. Para el ámbito vasco, aparte de la casa de Haro, se ocupa de "la casa de Ayala e de Salsedo»" de "la casa e linaje de los condes de Guebara $»^{99}$, de la "casa e linaje de Mendoça» ${ }^{100}$, y de "la casa e linaje de los Sarmientos» ${ }^{101}$, todas ellas poseedoras de señoríos. No nos atrevemos a interpretar por qué no incluye en esta nómina a los Múgica y a los Avendaño, también titulares de señorío ${ }^{102}$, aunque sospechemos que pueda ser a causa de una estrategia desprestigiante que permite al cronista equiparar su linaje con estos dos que son los que encabezan los bandos vizcaínos.

En cualquier caso, las nociones de solar y casa encarnan ese patrimonio colectivo para el conjunto de los miembros del linaje. Una idea de pertenencia que se manifiesta simbólica y materialmente en elementos como el sistema onomástico ${ }^{103} \mathrm{o}$ la heráldica, implicando en todos los casos una apropiación simbólica en la que se refleja bien la compleja interacción entre lo individual y lo colectivo en lo que Eduardo Pardo de Guevara ha definido como «modelo cultural» del linaje ${ }^{104}$. He aquí un ejemplo que se ofrece en la Crónica de Vizcaya:

E este don Rodrigo Sanches [de Salcedo] peleó con don Pero Furtado de Mendoça cabe Çadorra, e lo vençió cuando llevaban las bacas de su madre, e lo mató, e tomóle dies pañeles verdes que avían los de Mendoça, e para los de su linaje ${ }^{105}$.

La apropiación simbólica afecta a las armas y al nombre del linaje $\mathrm{e}^{106}$, al enterramiento, a las fundaciones e, incluso, a las «mujeres y linajes vinculados por matrimonio»

94 «De las casas e linajes de los cavalleros e señores que crecieron en el tiempo del rey don Enrique Cuarto yo no quiero fablar en sus fechos porque pertenecen a los coronistas del dicho señor rey don Enrique» (Libro, p. 725).

95 Libro, p. 705.

$96 \quad$ Libro, pp. 711 a 716.

97 De la Cerda, Luna, Alba, Aguilar, Portocarrero, Dávalos, etc. (Libro, p. 721), todos ellos, como los anteriores, vinculados a estados señoriales de diversa entidad.

98 Crónica, p. 54; "casa e linaje de los señores de la casa de Ayala» en Libro, p. 708.

99 Libro, p. 705.

100 Libro, p. 706.

101 Libro, p. 714.

102 Por ejemplo, «eredó este solar de Múgica e el señorío de Aramayona Gómez González, segund se contiene en el título del solar de Butrón» (Libro, p. 740).

103 Gerbet, La noblesse dans le Royaume de Castille, pp. 236-237.

104 "¿Hacia una nueva ciencia genealógica? Reflexiones para una renovación de sus métodos y objetivos». Medievalismo. Boletín de la Sociedad Española de Estudios Medievales, 1992, vol. 2, p. 180).

105 Crónica, p. 58.

106 Dos magníficas síntesis en: SÁNCHEz SAUs, Rafael. «De armerías, apellidos y estructuras de linaje». En la España Medieval, 1994, vol. 17, pp. 9-16; y Gerbet, Marie-Claude. Les noblesses espagnoles au Moyen Âge. $X I^{e}-X V^{e}$ siècle. Paris: Armand Colin, 1994, pp. 209 y ss. 
ARSENIO DACOSTA

como ha señalado Cristina Jular ${ }^{107}$. De todos ellos, el que tiene un papel especialmente relevante sobre el resto en las obras de García de Salazar es el patronazgo. Más allá de los casos particulares y por encima de su marcada perspectiva linajística (entiéndase, de su propio linaje), Lope García nos transmite una defensa colectiva de los derechos de patronazgo ligados a los linajes «de las montañas e tierras de Castilla Vieja e de Asturias de Santillana e Trasmiera e las Encartaciones e Álava e Vizcaya e Guipúzcoa e Navarra e Lavorte e sus arrededores»:

E moriendo estos tales edificadores de monesterios e quedando sus herederos, ordenaron de dar al mayor fijo heredero aquel monesterio con aquellas décimas, por que no se devidiese en sus erederos e por que compliese todas aquellas cosas qu'el tal edificador avía complido. E llamáronle patrón de aquel monesterio e en algunos d'ellos les llamaron avad del monesterio. E mandáronles que de lo que sobrase de aquellas décimas, complidos los dichos ornamentos e su mantenimiento, que diesen sendos yantares en el año aquellos sus hermanos e decendientes. E a estos yantares llamaron devisa, como se han llamado e llaman fasta agora ${ }^{108}$.

El patronazgo trasciende la idea expresada por el cronista y, de facto, es la manifestación más perfecta del poder de los parientes mayores de linaje. También de su naturaleza abiertamente feudal. Se le ha dado una gran importancia al «parentesco espiritual» en el Occidente europeo. Sin duda la tuvo, pero no menor, al menos para el ámbito castellano, que modalidades más o menos expresas de patronazgo ${ }^{109}$. El patronazgo no es, pues, ni una idea ni una institución, sino una práctica que sobrepasa los muros de la iglesia y se derrama por los valles y villas. Una práctica que se manifiesta en toda su potencia en la dialéctica jerarquizada entre el patrono y la comunidad, a un mismo tiempo creyentes, parientes, vecinos y deudos. En un sentido similar, el parentesco no es una estructura uniforme, sino un complejo conjunto de símbolos y prácticas, cuya coherencia debe ser desvelada con el esfuerzo de historiadores y antropólogos ${ }^{110}$.

107 «Porque tengo obligación: genealogía, escritura e identidad nobiliarias. Los Velasco». En CASTILLO Lluch, Mónica y López IzQuierdo, Marta (eds.). Modelos latinos en la Castilla medieval. Madrid-Frankfurt am Main: Iberoamericana-Vervuert, 2010, pp. 307-330, en especial, pp. 318-332. Los análisis de apropiación simbólica del patrimonio de un linaje por otro fueron tempranamente desarrollados por José Mattoso y sus discípulos. Véase, a modo de ejemplo, Vasconcelos e Sousa, Bernardo. «Los Pimentel y la construcción de una memoria linajística». En Dacosta, Arsenio; Prieto Lasa, José Ramón y Díaz de Durana, José Ramón (coords.). La conciencia de los antepasados. La construcción de la memoria de la nobleza en la Baja Edad Media. Madrid: Marcial Pons, 2014, passim.

108 Libro, pp. 938-939.

109 «Debemos considerar la utilización de las instituciones eclesiásticas por parte de linajes nobles como estrategia de expansión económica y social, en un sentido muy amplio, y que esas estrategias y la profundidad de su acción varían según se trate de alta o baja nobleza» (PAstor DE Togneri, Reyna et álii. "Baja nobleza: aproximación a la historiografía europea y propuestas para una investigación». Historia Social, 1994, vol. 20, p. 40).

110 Una propuesta en este sentido en Monsalvo Antón, José María. «Antropología política e historia: costumbre y derecho; comunidad y poder; aristocracia y parentesco; rituales locales y espacios simbólicos». En López OJeda, Esther (coord.). Nuevos temas, nuevas perspectivas en historia medieval. XXV Semana de Estudios Medievales de Nájera. Logroño: Instituto de Estudios Riojanos, 2015, pp. 105-158. 
ARSENIO DACOSTA

«PODEROSO EN PARIENTES E RENTAS»: CONCEPTOS, DISCURSOS Y PRÁCTICAS SOBRE EL LINAJE

EN LOPE GARCÍA DE SALAZAR

Hemos centrado nuestro análisis en las obras de Lope García de Salazar, un autor singular perteneciente a una nobleza -la de la Cornisa Cantábrica- que ha sido considerada "très originale» ${ }^{111}$. Cierto es que hay elementos para tal asombro -como la declaración de la «universal hidalguía» vizcaína en 1527-, pero habría que objetivar dichas particularidades y, sobre todo, los puntos de conexión con otras realidades próximas y extrapeninsulares. En relación al linaje no percibimos grandes divergencias con otros modelos contemporáneos, a lo más de detalle (en ciertas prácticas de hidalguización a través de la alianza) ${ }^{112}$ y, quizá, de escala (como lo que se refiere a la duración e intensidad de la violencia banderiza $)^{113}$. De hecho, creemos que la conceptualización de «linaje» que encontramos en las obras de García de Salazar no difiere gran cosa de las que contienen las escasas obras escritas o encargadas por jefes de linaje como él ${ }^{114}$.

Dos son los enfoques que han primado hasta la fecha en el estudio del linaje: el que lo interpretaba como una forma de organización del parentesco característico de la nobleza, y el que apostaba por analizar los elementos de la llamada "cultura del linaje». Hemos tratado de evitar ambos, ya que, por mucho que sean enriquecedores y contribuyan a acumular necesarios estudios de caso, son limitativos respecto de la conceptualización de las realidades sociales que expresa el linaje. De hecho, el primer enfoque se ha revelado un callejón sin salida toda vez que la propia noción de parentesco está sujeta a una profunda crítica por parte de antropólogos y también medievalistas ${ }^{115}$. El segundo, esto es, interpretar el linaje en términos de "cultura», aunque esté de moda, plantea evidentes limitaciones desde una perspectiva antropológica ${ }^{116}$. Hacemos nuestra la brillante frase del hispanista James Casey en la que se resume la naturaleza a un tiempo material e ideológica del concepto que nos proponíamos analizar en este artículo: «el linaje arropa culturalmente a quien lo posee» ${ }^{117}$. Llegamos así al habitus.

111 Gerbet, Les noblesses espagnoles, p. 88.

112 Como las descritas en Díaz de Durana Ortiz de Urbina, José Ramón. Anonymous Noblemen: the generalization of Hidalgo status in the Basque Country (1250-1525). Turnhout: Brepols, 2011.

113 Díaz de Durana Ortiz de urbina, José Ramón. «Luchas sociales y luchas de bandos en el País Vasco durante la Baja Edad Media». Historiar: Revista Trimestral de Historia, 1999, vol. 3, pp. 154-171.

114 Un análisis panorámico para Castilla en DAcostA, "A propósito de un aparente silencio».

115 Una perspectiva deconstructiva del parentesco en Kuper, Adam. «Descent theory». En The Reinvention of Primitive Society: Transformations of A Myth. London: Routledge, 2005, pp. 163-178. En el ámbito del medievalismo remito al trabajo de Guerreau-Jalabert, Anita; Le Jean, Régine y Morsel, Joseph. «Familles et parents. De l'histoire de la famille à l'anthropologie de la parenté». En Sснмiтt, Jean-Claude y Oexle, Otto Gerhard (eds.). Les tendances actuelles de l'histoire du Moyen Âge en France et en Allemagne. Paris: Publications de la Sorbonne, 2002, pp. 433-446.

116 Wells-Furby, Bridget. "The Origin of the 'Name and Arms' Clause and the Development of the Lineage Culture in Fourteenth-Century England». Nottingham Medieval Studies, 2015, vol. 59, pp. 77-111. En nuestro país, Eduardo Pardo De Guevara restringía su idea del «modelo cultural» del linaje al «conjunto de valores y conceptos que rigen su propia dinámica histórica» (« Hacia una nueva ciencia genealógica?», p. 180).

117 La cita la transmite Hernández Franco, "Consideraciones y propuestas», p. 21. Agradecemos al profesor Hernández Franco sus amables aclaraciones al respecto. 
ARSENIO DACOSTA

En 1978 Pierre Bourdieu participó en el homenaje que la revista L'Arc hizo de la persona y obra de Georges Duby ${ }^{118}$. El sociólogo reconocía el inspirador análisis que había hecho Duby sobre la teoría de los tres órdenes. Esa admiración la compartimos todos los medievalistas, pero, lamentablemente, su modelo linajístico no funciona universalmente ${ }^{119}$. El problema es, a nuestro juicio, de orden metodológico: el linaje es una realidad recursiva, una manifestación de la acción -como hubiera gustado Pierre Bourdieu- $y$, en consecuencia, su análisis no puede realizarse desde un planteamiento deductivo, partiendo de una premisa, por mucho que esta se ajuste a una definición -de las varias posibles- reflejada en la documentación. Se impone, pues, una revisión constructivista de la noción de linaje $\mathrm{e}^{120}$.

Ninguno de los elementos caracterizadores del linaje tiene sentido histórico si no se identifica con unas determinadas relaciones sociales. De hecho, dichas señas de identidad del linaje, que se proyectan hacia lo que Joseph Morsel denomina «sociogénesis de la nobleza», deben ser descritas en términos contingentes o, si se prefiere, en relación a prácticas y relaciones sociales concretas ${ }^{121}$. Esa contingencia puede ser entendida en dos sentidos que complementan la noción del habitus en el linaje. De un lado, contingencia como temporalidad, ya que no es lo mismo el linaje del siglo xIII que el del xv. De otro, contingencia como negociación, clave de comprensión de los procesos sociales que convergen y se proyectan hacia y desde el linaje. Tal y como hubiera expresado el Aquinate, podríamos definir habitus como una "metafísica de los hábitos», una cualidad definida por la acción social ${ }^{122}$.

Hemos visto que en Lope la noción de «linaje» trasciende completamente el sentido de familia, sea cual sea la definición que tomemos de este -también-controvertido concepto. Pero lo hace indisolublemente unida a una ética particular, la del «más valer». Esta «razón del linaje» es la que defiende Lope en su obra: el pariente mayor debe garantizar por todos los medios la supervivencia y acrecentamiento del linaje. En este sentido, la vinculación al primogénito varón es, a nuestro juicio, una herramienta más en estas estrategias que se sintetizan en el concepto de «más valer». Cierto es que esa vinculación al primogénito, en cualquiera de sus modalidades, puede interpretarse en términos de institución jurídica, pero ¿a esto se reduce, por ejemplo, un mayorazgo?

118 Bourdieu, "Capital symbolique et classes sociales».

119 Una crítica en VASCONCElos E Sousa, Bernardo. «Linhagem e identidade social na nobreza medieval portuguesa (séculos XIII-XIV)». Hispania. Revista Española de Historia, 2007, vol. 67, n. o 227, pp. 881-898.

120 Es la línea que viene proponiendo Joseph Morsel en los últimos ańos, valorando la genealogía de los conceptos, la de nuestra propia disciplina y la de las prácticas históricas de escritura y archivo en la definición del linaje («Le médiéviste, le lignage et l'effect de réel. La construction du Geschlecht par l'archive en Haute-Allemagne à partir de la fin du Moyen Âge». Revue de Synthèse, 2004, vol. 125, pp. 83-110).

121 Morsel, Joseph. «La construction sociale des identités dans l'aristocratie franconienne aux XIV et $\mathrm{XV}^{\mathrm{e}}$ siècles: individuation ou identification?». En Bedos-RezaK, Brigitte M. y Iogna-Prat, Dominique (dirs.). L'individu au Moyen Âge. Individuation et individualisation avant la modernité. Paris: Aubier, 2005, pp. 79-99.

122 Fernández Fernández, José Manuel. «Habitus y acción social en Tomás de Aquino y Pierre Bourdieu». En Méndez Francisco, Luis (ed.). La ética, aliento de lo eterno. Salamanca: Editorial San Esteban-Universidad Complutense de Madrid, 2003, pp. 232-233. 
ARSENIO DACOSTA

«PODEROSO EN PARIENTES E RENTAS»: CONCEPTOS, DISCURSOS Y PRÁCTICAS SOBRE EL LINAJE

EN LOPE GARCÍA DE SALAZAR

El linaje es una realidad performativa ${ }^{123}$, sostenida por un juego de dinámicas internas y estrategias externas. Es espacio de socialización y de sociabilidad ${ }^{124}$. Un ejemplo manifiesto lo hallamos en la -por lo general- autorrepresión de aquellos miembros del linaje marginados de los beneficios -y obligaciones- del liderazgo del linaje en pos de los intereses colectivos o "espíritu de familia» en palabras del propio Bourdieu ${ }^{125}$. Hemos visto en Lope García de Salazar que los segundones y bastardos acrecientan y promueven el capital simbólico de los linajes cantábricos por distintos mecanismos, y sabemos que esto no fue muy diferente en otras regiones ${ }^{126}$. Si ampliamos el círculo de la hegemonía del pariente mayor hasta el límite de su clientela, hallaremos además la fuerza de choque y el núcleo productivo del linaje. Por ello no creemos posible seguir considerando las clientelas como grupos "paranobiliarios» $\mathrm{o}$ "satélite» ${ }^{127}$; los «parientes» son, como expresa el propio Lope García de Salazar, uno de los fundamentos del poder del linaje. También un vector de conflictos y oportunidades sociales en el seno de la nobleza ${ }^{128}$.

Por ello cabe redefinir la «inflexion patrilinéaire», esa tendencia que se va consolidando a finales de la Edad Media, no como el mecanismo caracterizador de la lógica del parentesco nobiliario, sino como manifestación de la aludida hegemonía del pariente mayor, de la dominación social -en equilibrio o no ${ }^{129}$ - que se articula en el seno del linaje. El linaje se organiza sobre una red de relaciones de parentesco, pero también sobre lógicas de producción y vecindad, sobre agregación simbólica y persecución de objetivos políticos ${ }^{130}$. Desde la perspectiva analítica aquí adoptada es y se manifiesta a través del habitus o, como hubiera dicho Julio Caro Baroja, sobre una particular y agonal «teoría del linaje» a la que Lope García de Salazar y sus contemporáneos se referían como «más valer».

\section{REFERENCIAS BIBLIOGRÁficAS}

Achón InsAusti, José Ángel. “"Valer más” o “valer igual”: estrategias banderizas y corporativas en la constitución de la provincia de Guipúzcoa». En El Pueblo Vasco en el Renacimiento (14911521). Bilbao: Mensajero, 1994, pp. 55-76.

123 WaCQUANT, Loïc. «Poniendo al habitus en su lugar: réplica del simposio». Revista Latinoamericana de Estudios sobre Cuerpos, Emociones y Sociedad, 2014, vol. 15, pp. 40-52.

124 Una magnífica síntesis en Beceiro Pita y Córdoba de la Llave, Parentesco, poder y mentalidad, pp. 109-125.

125 Bourdieu, Pierre. Razones prácticas. Sobre la teoría de la acción. Barcelona: Anagrama, 1997, p. 197.

126 Framiñán Santas, Ana M. a y Presedo Garazo, Antonio. «Estructuras de parentesco de la nobleza gallega en 1350-1600: una primera valoración». Obradoiro de Historia Moderna, 2005, vol. 14, pp. 109-140, en especial, p. 134.

127 Así se expresa al respecto Gerbet, La noblesse dans le Royaume de Castille, p. 309.

128 Sin salir de Galicia, remito al magnífico trabajo de Pallares Méndez, M. a del Carmen y Portela SiLva, Ermelindo. «Los mozos nobles. Grandes hombres, si fueran hijos solos». Revista d'Història Medieval, 1994, vol. 5, pp. 55-74.

129 Guerreau-Jalabert; Le Jean y Morsel, «Familles et parents», p. 440.

130 En el ámbito urbano castellano ha quedado claro el sentido eminentemente político de las distintas modalidades de linajes y bandos. La bibliografía para Castilla es muy abundante, por lo que remitimos a un único trabajo de referencia: Monsalvo Antón, José María. «Parentesco y sistema concejil. Observaciones sobre la funcionalidad política de los linajes urbanos en Castilla y León (siglos XIII-Xv)». Hispania. Revista Española de Historia, 1993, vol. 53, n. ${ }^{\circ} 185$, pp. 937-969. 
ARSENIO DACOSTA

Achón Insausti, José Ángel. "A voz de concejo». Linaje y corporación urbana en la constitución de la Provincia de Gipuzkoa: los Báñez y Mondragón, siglos XIII-XVI. San Sebastián: Diputación Foral de Gipuzkoa, 1995.

Achón Insausti, José Ángel. «Los parientes mayores». Iura Vasconiae, 2006, vol. 3, pp. 221-247.

Aguirre Gandarias, Sabino. Las dos primeras crónicas de Vizcaya. Estudios, textos criticos y apéndices. Bilbao: Caja de Ahorros Vizcaína, 1986.

Aguirre Gandarias, Sabino. Lope García de Salazar. El primer historiador de Bizkaia (13991476). Bilbao: Diputación Foral de Bizkaia, 1994.

Alonso Pedraz, Martín. Diccionario medieval español. Desde las Glosas Emilianenses y Silenses (s. X) hasta el siglo XV. Salamanca: Universidad Pontificia de Salamanca, 1986.

Atienza Hernández, Ignacio. «Teoría y administración de la casa, linaje, familia extensa, ciclo vital y aristocracia en Castilla (s. XVI-XIx)». En Chacón Jiménez, Francisco; Hernández Franco, Juan y Peñafiel Ramón, Antonio (coords.). Familia, grupos sociales y mujer en España (s. XV-XIX). Murcia: Universidad de Murcia, 1991, pp. 13-48.

Beceiro Pita, Isabel. «El escrito, la palabra y el gesto en las tomas de posesión señoriales». Studia Historica. Historia Medieval, 1994, vol. 12, pp. 53-82.

Beceiro Pita, Isabel. «La conciencia de los antepasados y la gloria del linaje en la Castilla bajomedieval». En Pastor, Reyna (dir.). Relaciones de poder, de producción y de parentesco en la Edad Media y Moderna. Madrid: Consejo Superior de Investigaciones Científicas, 1990, pp. 329-350.

Beceiro Pita, Isabel y Córdoba de la Llave, Ricardo. Parentesco, poder y mentalidad. La nobleza castellana, siglos XII-XV. Madrid: Consejo Superior de Investigaciones Científicas, 1990.

Bizzarri, Hugo O. Castigos del rey don Sancho IV. Frankfurt am Main-Madrid: Vervuert-Iberoamericana, 2001.

Bourdieu, Pierre. «Capital symbolique et classes sociales». L'Arc, 1978, vol. 72, pp. 13-19.

Bourdieu, Pierre. «Les stratégies matrimoniales dans le système de reproduction». Annales. Économies, Sociétés, Civilisations, 1972, vol. 27, pp. 1105-1125.

Bourdieu, Pierre. Esquisse d'une théorie de la pratique. Précédé de trois études d'ethnologie Kabyle. Ginebra: Droz, 1972.

Bourdieu, Pierre. Le sens pratique. Paris: Minuit, 1980.

Bourdieu, Pierre. Razones prácticas. Sobre la teoría de la acción. Barcelona: Anagrama, 1997.

Brunner, Otto. "La "casa grande" y la "Oeconomica" de la vieja Europa». Prismas. Revista de Historia Intelectual, 2010, vol. 14, pp. 117-136.

Burke, Peter. ¿Qué es la historia cultural? Barcelona: Paidós, 2006.

Capdevielle, Julieta. "El concepto de habitus: "con Bourdieu y contra Bourdieu"». Anduli. Revista Andaluza de Ciencias Sociales, 2011, vol. 10, pp. 31-45.

Caro Baroja, Julio. De arquetipos y leyendas. Dos tratados introductorios. Madrid: Círculo de Lectores, 1989.

Caro Baroja, Julio. Linajes y bandos. A propósito de la nueva edición de "Las Bienandanzas e Fortunas». Bilbao: Diputación Foral de Vizcaya, 1956.

Carrasco Manchado, Ana Isabel. «Nuevas herramientas para la historia de la Edad Media hispánica: los corpus textuales informatizados». En la España Medieval, 2011, vol. 34, pp. 343372.

Casey, James. «La invención de la comunidad y la historia social». Pedralbes. Revista d'Història Moderna, 2003, vol. 23, n. ${ }^{\circ}$ 2, pp. 779-796.

Chacón Jiménez, Francisco. «Propuestas teóricas y organización social desde la Historia de la Familia en la España Moderna». Studia Historica. Historia Moderna, 1998, vol. 18, pp. 17-28. 
ARSENIO DACOSTA

«PODEROSO EN PARIENTES E RENTAS»: CONCEPTOS, DISCURSOS Y PRÁCTICAS SOBRE EL LINAJE

EN LOPE GARCÍA DE SALAZAR

Contreras Contreras, Jaime. «Linaje y cambio social: la manipulación de la memoria». Historia Social, 1995, vol. 21, pp. 105-124.

Crouch, David. «The Historian, Lineage and Heraldry, 1050-1250». En: Coss, Peter y Keen, Maurice (eds.). Heraldry, Pageantry and Social Display in Medieval England. Woodbridge: Boydell, 2002, pp. 17-38.

Crouch, David. The Birth of Nobility: Constructing Aristocracy in England and France, 900-1300. New York: Routledge, 2014.

Dacosta, Arsenio (ed.). El "Libro del linaje de los señores de Ayala» y otros textos genealógicos. Materiales para el estudio de la conciencia del linaje en la Baja Edad Media. Bilbao: Universidad del País Vasco, 2007.

Dacosta, Arsenio. "A propósito de un aparente silencio: la memoria genealógica escrita de la nobleza peninsular en la baja Edad Media». Tiempos Modernos, 2016, vol. 32 (en prensa).

Dacosta, Arsenio. "De dónde sucedieron unos en otros. La historia y el parentesco vistos por los linajes vizcaínos bajomedievales». Vasconia, 1999, vol. 28, pp. 57-70.

Dacosta, Arsenio. "De la anomalía a lo extraordinario: nobleza, linaje y escritura genealógica en Castilla (siglos XIII-XIv)». Hispania. Revista Española de Historia, 2015, vol. 75, n. ${ }^{\circ}$ 251, pp. 617-640.

Dacosta, Arsenio. «De la conciencia del linaje a la defensa estamental. Acerca de algunas narrativas nobiliarias vascas». Medievalista [en línea], 2010, vol. 8 [disponible en: http://www2. fcsh.unl.pt/iem/medievalista/MEDIEVALISTA8/dacosta8007.html].

Dacosta, Arsenio. «Las fuentes de renta del linaje de Salazar: aportación al estudio de las haciendas nobiliarias en la corona de Castilla durante la Baja Edad Media». En Díaz de Durana, José Ramón y Reguera, Iñaki (eds.). Lope García de Salazar: banderizo y cronista. Portugalete: Ayuntamiento de Portugalete, 2002, pp. 41-64.

Dacosta, Arsenio. Los linajes de Bizkaia en la Baja Edad Media: poder, parentesco y conflicto. Bilbao: Universidad del País Vasco, 2004.

Díaz de Durana Ortiz de Urbina, José Ramón y Fernández de Larrea y Rojas, Jon Andoni. «El discurso político de los protagonistas de las luchas sociales en el País Vasco al final de la Edad Media». En Alfonso Antón, Isabel; Escalona Monge, Julio; Martin, Georges (coords.). Lucha política: condena y legitimación en la España medieval. Lyon: ENS Éditions, 2004, pp. 313-336.

Díaz de Durana Ortiz de Urbina, José Ramón. «Luchas sociales y luchas de bandos en el País Vasco durante la Baja Edad Media». Historiar: Revista Trimestral de Historia, 1999, vol. 3 , pp. 154-171.

Díaz de Durana Ortiz de Urbina, José Ramón; Dacosta, Arsenio. «La dimensión social del liderazgo del linaje: solidaridad, poder y violencia (País Vasco, siglo xv)». Studia Zamorensia, 2013, vol. 12, pp. 87-105.

Díaz de Durana Ortiz de Urbina, José Ramón. Anonymous Noblemen: the generalization of Hidalgo status in the Basque Country (1250-1525). Turnhout: Brepols, 2011.

Evans-Pritchard, Edward E. Ensayos de Antropología Social. Madrid: Siglo XXI.

Fernández Fernández, José Manuel. «Habitus y acción social en Tomás de Aquino y Pierre Bourdieu». En Méndez Francisco, Luis (ed.). La ética, aliento de lo eterno. Salamanca: Editorial San Esteban-Universidad Complutense de Madrid, 2003, pp. 231-248.

Fernández FernándeZ, José Manuel. «Habitus y sentido práctico: la recuperación del agente en la obra de Bourdieu». Cuadernos de Trabajo Social, 2003, vol. 16, pp. 7-28.

Folger, Robert. Generaciones y semblanzas: Memory and Genealogy in Medieval Iberian Historiography. Tübingen: Gunter Narr, 2003. 
ARSENIO DACOSTA

Foucault, Michel. Un diálogo sobre el poder y otras conversaciones. Madrid: Alianza Editorial, 1981.

Framiñán Santas, Ana M. a y Presedo Garazo, Antonio. «Estructuras de parentesco de la nobleza gallega en 1350-1600: una primera valoración». Obradoiro de Historia Moderna, 2005, vol. 14, pp. 109-140.

García FernÁNDEZ, Ernesto. «El linaje Avendaño: causas y consecuencias de su ascenso social en la Baja Edad Media». Anuario de Estudios Medievales, 2007, vol. 37, n. ${ }^{\circ} 2$, pp. 527-561.

Gerbet, Marie-Claude. «Majorat, stratégie familiale et pouvoir royal en Castille d'après quelques exemples pris en Extrémadure à la fin du Moyen Âge». En Les Espagnes médiévales. Aspects économiques et sociaux. Mélanges offerts à Jean Gautier Dalché. Nice: Les Belles Lettres-Université de Nice, 1983, pp. 257-276.

Gerbet, Marie-Claude. La noblesse dans le Royaume de Castille. Etude sur ses structures sociales en Estrémadure (1454-1516). Paris: Publications de la Sorbonne, 1979.

Gerbet, Marie-Claude. Les noblesses espagnoles au Moyen Agge. XI $I^{\top} X V^{e}$ siècle. Paris: Armand Colin, 1994.

González Cuevas, Pedro Carlos. «Habitus e ideología. El pensamiento político de Francisco Moreno y Herrera, Marqués de la Eliseda». Cuadernos de Historia Contemporánea, 1996, vol. 18, pp. 83-114.

Goody, Jack. La evolución de la familia y del matrimonio en Europa. Barcelona: Herder, 1986.

Guerreau-Jalabert, Anita. "La Parenté dans l'Europe médiévale et moderne: à propos d'une synthèse récente». L'Homme, 1989, vol. 29, n. ${ }^{\circ} 110$, pp. 69-93.

Guerreau-Jalabert, Anita. «Parentesco». En Le Goff, Jacques y Schmitt, Jean-Claude (dirs.). Diccionario razonado del Occidente Medieval. Madrid: Akal, 2003, pp. 626-636.

Guerreau-Jalabert, Anita; Le Jean, Régine y Morsel, Joseph. «Familles et parents. De l'histoire de la famille à l'anthropologie de la parenté». En Schmitt, Jean-Claude y OexLe, Otto Gerhard (eds.). Les tendances actuelles de l'histoire du Moyen Âge en France et en Allemagne. Paris: Publications de la Sorbonne, 2002, pp. 433-446.

Guillén Berrendero, José Antonio. «La tratadística nobiliaria como espejo de nobles. El ejemplo de Juan Benito Guardiola y su Tratado de Nobleza de 1591». Brócar, 2002, vol. 26, pp. 81-106.

Hernández Franco, Juan. «Consideraciones y propuestas sobre linaje y parentesco». En Familia, parentesco y linaje. Congreso Internacional Historia de la Familia: Nuevas perspectivas sobre la sociedad europea. Murcia: Universidad de Murcia, 1997, pp. 19-29.

Hernández Franco, Juan. Sangre limpia, sangre española. El debate de los estatutos de limpieza (Siglos XV-XVII). Madrid: Cátedra, 2011.

Hernández Franco, Juan y Rodríguez Pérez, Raimundo A. «Estrategias, prácticas y actores: avances en los estudios sobre linajes castellanos, a partir de la sociohistoria». Magallánica. Revista de Historia Moderna, 2015, vol. 2, pp. 7-29.

Hespanha, António Manuel. História de Portugal. Dir. José Mattoso. Vol. 4: o Antigo Régime (1620-1807). Lisboa: Estampa, 1997.

Heusch, Carlos. «La pluma al servicio del linaje. El desarrollo de los nobiliarios en la Castilla Trastámara». e-Spania. Revue Électronique d'Études Hispaniques Médiévales et Modernes, 2011, vol. 11 [disponible en: https://e-spania.revues.org/20313].

Hidalgo de Cisneros, Concepción et álii (eds.). Fuentes jurídicas medievales del Señorio de Vizcaya. Cuadernos Legales, Capitulos de la Hermandad y Fuero Viejo (1342-1506). San Sebastián: Eusko Ikaskuntza, 1986.

Ilarregui, Pablo y Lapuerta, Segundo. Fuero General de Navarra. Pamplona: Imprenta Provincial, 1869. 
ARSENIO DACOSTA

«PODEROSO EN PARIENTES E RENTAS»: CONCEPTOS, DISCURSOS Y PRÁCTICAS SOBRE EL LINAJE

EN LOPE GARCÍA DE SALAZAR

Jular Pérez-Alfaro, Cristina. «Porque tengo obligación: genealogía, escritura e identidad nobiliarias. Los Velasco». En Castillo Lluch, Mónica y López Izquierdo, Marta (eds.). Modelos latinos en la Castilla medieval. Madrid-Frankfurt am Main: Iberoamericana-Vervuert, 2010, pp. 307-330.

Kuper, Adam. "Descent theory». En The Reinvention of Primitive Society: Transformations of A Myth. London: Routledge, 2005, pp. 163-178.

Kuper, Adam. Cultura. La versión de los antropólogos. Barcelona: Paidós, 2001.

Ladero Quesada, Miguel Ángel. «Linajes, bandos y parcialidades en la vida política de las ciudades castellanas (siglos XIV y Xv)». En Bandos y querellas dinásticas en España al final de la Edad Media. Actas del Coloquio celebrado en la Biblioteca Española de París los días 15 y 16 de mayo de 1987. París: Ministerio de Asuntos Exteriores, 1991, pp. 105-134.

LÉvi-Strauss, Claude. Las estructuras elementales del parentesco. Barcelona: Paidós, 1998.

Líbano Zumalacárregui, Ángeles y Villacorta Macho, Consuelo. «Aproximación léxica a las estructuras y grupos sociales en el espacio geográfico vascongado (siglos XV y XVI)». Revista de Investigación Lingüística, 2008, vol. 11, pp. 165-188.

Marín Paredes, José Antonio. «Semejante Pariente Mayor». Parentesco, solar, comunidad y linaje en la institución de un Pariente Mayor en Gipuzkoa: los señores del solar de Oñaz y Loyola (siglos XIV-XVI). San Sebastián: Diputación Foral de Gipuzkoa, 1998.

Martin, Georges. "Control regio de la violencia nobiliaria. La caballería según Alfonso X de Castilla (comentario al título XXI de la Segunda partida)». En Alfonso Antón, Isabel; EsCalona Monge, Julio y Martin, Georges (coords.). Lucha politica: condena y legitimación en la España medieval. Lyon: ENS Éditions, 2004, pp. 219-234.

Martínez Gorriarán, Carlos. Casa, provincia, rey: para una historia de la cultura del poder en el País Vasco. Irún: Alberdania, 1993.

Miranda, José Carlos Ribeiro. «O argumento da linhagem na literatura ibérica do séc. XIII». e-Spania. Revue Électronique d'Études Hispaniques Médiévales, 2011, vol. 11 [consultado el 22/01/2016; disponible en: http:/ e-spania.revues.org/20347].

Mitxelena, Koldo. Textos arcaicos vascos. San Sebastián: Diputación Foral de Gipuzkoa-Universidad del País Vasco, 1990.

Monsalvo Antón, José María. «Antropología política e historia: costumbre y derecho; comunidad y poder; aristocracia y parentesco; rituales locales y espacios simbólicos». En López OJeDA, Esther (coord.). Nuevos temas, nuevas perspectivas en historia medieval. XXV Semana de Estudios Medievales de Nájera. Logroño: Instituto de Estudios Riojanos, 2015, pp. 105-158.

Monsalvo Antón, José María. «Parentesco y sistema concejil. Observaciones sobre la funcionalidad política de los linajes urbanos en Castilla y León (siglos XIII-Xv)». Hispania. Revista Española de Historia, 1993, vol. 53, n. ${ }^{\circ}$ 185, pp. 937-969.

Morsel, Joseph. «Le médiéviste, le lignage et l'effect de réel. La construction du Geschlecht par l'archive en Haute-Allemagne à partir de la fin du Moyen Âge». Revue de Synthèse, 2004, vol. 125, pp. 83-110.

Morsel, Joseph. "La construction sociale des identités dans l'aristocratie franconienne aux XIV et $\mathrm{XV}^{\mathrm{e}}$ siècles: individuation ou identification?». En Bedos-RezaK, Brigitte M. y Iogna-Prat, Dominique (dirs.). L'individu au Moyen Âge. Individuation et individualisation avant la modernité. Paris: Aubier, 2005, pp. 79-99.

Morsel, Joseph. La aristocracia medieval: La dominación social en Occidente (siglos V-XV). València: Universitat de València, 2008.

Munita Loinaz, José Antonio et álii. "En tiempo de ruidos e bandos»: nuevos textos para el estudio de los linajes vizcainos: los Barroeta de la merindad de Marquina (1355-1547). Bilbao: Universidad del País Vasco, 2014. 
ARSENIO DACOSTA

"PODEROSO EN PARIENTES E RENTAS»: CONCEPTOS, DISCURSOS Y PRÁCTICAS SOBRE EL LINAJE EN LOPE GARCÍA DE SALAZAR

MuÑoz Gómez, Víctor. «Domésticos, "casa”, y “afinidad” en la Castilla bajomedieval. ¿Una historia sin registros?». Mélanges de la Casa de Velázquez, 2015, vol. 45, n. ${ }^{\circ} 2$, pp. 15-32.

Pallares Méndez, M. a del Carmen y Portela Silva, Ermelindo. «Los mozos nobles. Grandes hombres, si fueran hijos solos». Revista d'Història Medieval, 1994, vol. 5, pp. 55-74.

PARDO DE GueVARA Y VALDÉs, Eduardo. «HHacia una nueva ciencia genealógica? Reflexiones para una renovación de sus métodos y objetivos». Medievalismo. Boletín de la Sociedad Española de Estudios Medievales, 1992, vol. 2, pp. 171-186.

PASTOR DE Togneri, Reyna et álii. «Baja nobleza: aproximación a la historiografía europea y propuestas para una investigación». Historia Social, 1994, vol. 20, pp. 23-46.

PÉREZ, Mariel. «En torno a las estructuras de parentesco de la aristocracia castellanoleonesa. Revisión de los modelos interpretativos dominantes». Anales de Historia Antigua, Medieval y Moderna, 2010, vol. 42, pp. 153-174.

Quintanilla Raso, María Concepción. «Propiedad vinculada y enajenaciones. Métodos y lógicas nobiliarias en la Castilla tardomedieval». Historia. Instituciones. Documentos, 2004, vol. 31, pp. 493-510.

RadCLIFFe-Brown, Alfred R. Estructura y función en la sociedad primitiva. Barcelona: Península, 1974.

Ramírez Vaquero, Eloísa. Solidaridades nobiliarias y conflictos políticos en Navarra, 1387-1464. Pamplona: Gobierno de Navarra, 1990.

Ramos y Loscertales, José M. ${ }^{a}$ (ed.). Fuero de Viguera y Val de Funes. Salamanca: Universidad de Salamanca, 1956.

Rosa, Maria de Lurdes. As almas herdeiras. Fundação de capelas fúnebres e afirmação da alma como sujeito de direito (Portugal, 1400-1521). Lisboa: Imprensa Nacional-Casa da Moeda, 2012.

Rosa, Maria de Lurdes. O Morgadio em Portugal, sécs. XIV-XV. Modelos e práticas de comportamento linhagistico. Lisboa: Editorial Estampa, 1995.

Ruiz, Teófilo F. Discursos de sangre y parentesco en Castilla durante la Baja Edad Media y la Época Moderna. Santander: Universidad de Cantabria, 2015.

SÁnchez León, Pablo. «Aspectos de una teoría de la competencia señorial: organización patrimonial, redistribución de recursos y cambio social». Hispania. Revista Española de Historia, 1993, vol. 53, n. ${ }^{\circ} 185$, pp. 885-905.

Sánchez Saus, Rafael. «De armerías, apellidos y estructuras de linaje». En la España Medieval, 1994, vol. 17, pp. 9-16.

Sснмiтt, Jean-Claude. La raison des gestes dans l'Occident médiéval. Paris: Gallimard, 1990.

Sottomayor-Pizarro, José Augusto de. «Linhagem e estruturas de parentesco». e-Spania. Revue Électronique d'Études Hispaniques Médiévales, 2011, vol. 11 [disponible en: https://e-spania. revues.org/20366].

Teuscher, Simon. («Politics of Kinship in the City of Bern at the End of the Middle Ages». En Warren, David; Teuscher, Simon y Mathieu, Jon (eds.). Kinship in Europe: Approaches to Long-Term Development (1300-1900). New York-Oxford: Berghahn Books, 2007, pp. 76-90.

Val Valdivieso, María Isabel del. «La solidaridad familiar en Vizcaya en el siglo XV». En Congreso de Estudios Históricos «Vizcaya en la Edad Media». San Sebastián: Eusko Ikaskuntza, 1986, pp. 333-337.

VASCONCElOS E SousA, Bernardo. «Linhagem e identidade social na nobreza medieval portuguesa (séculos XIII-XIV)». Hispania. Revista Española de Historia, 2007, vol. 67, n. ${ }^{\circ}$ 227, pp. 881-898.

Vasconcelos E Sousa, Bernardo. «Los Pimentel y la construcción de una memoria linajística». En Dacosta, Arsenio; Prieto Lasa, José Ramón y Díaz de Durana, José Ramón (coords.). 
ARSENIO DACOSTA

«PODEROSO EN PARIENTES E RENTAS»: CONCEPTOS, DISCURSOS Y PRÁCTICAS SOBRE EL LINAJE

EN LOPE GARCÍA DE SALAZAR

La conciencia de los antepasados. La construcción de la memoria de la nobleza en la Baja Edad Media. Madrid: Marcial Pons, 2014, pp. 175-200.

Vidal-Abarca, Juan. Los Herrán: historia y genealogía de una familia vasca. Vitoria: Diputación Foral de Álava, 1993.

Villacorta, Consuelo. Libro de las buenas andanças e fortunas que fizo Lope García de Salazar. Bilbao: Universidad del País Vasco, 2015.

WaCQUANT, Loïc. «Poniendo al habitus en su lugar: réplica del simposio». Revista Latinoamericana de Estudios sobre Cuerpos, Emociones y Sociedad, 2014, vol. 15, pp. 40-52.

WACQUANT, Loïc. «Symbolic power and group-making: on Pierre Bourdieu’s reframing of class». Journal of Classical Sociology, 2013, vol. 13, n. ${ }^{\circ}$ 2, pp. 274-291.

Wells-Furby, Bridget. «The Origin of the 'Name and Arms' Clause and the Development of the Lineage Culture in Fourteenth-Century England». Nottingham Medieval Studies, 2015, vol. 59, pp. 77-111.

Wulf, Christoph. Antropología. Historia, cultura, filosofía. Barcelona: Anthropos, 2008. 
